\title{
Polyurethane microparticles for stimuli response and reduced oxidative degradation in highly porous shape memory polymers
}

\author{
AC Weems ${ }^{1 *}, \mathrm{~W} \mathrm{Li}^{2}$, DJ Maitland ${ }^{1}, \mathrm{LM} \mathrm{Calle}^{2}$ \\ 1. Department of Biomedical Engineering, Texas A\&M University, College Station, TX, \\ 77840
}

2. Corrosion Technology Laboratory, NASA, Kennedy Space Center, FL, 32899

\begin{abstract}
Shape memory polymers (SMPs) have been found to be promising biomaterials for a variety of medical applications; however, the clinical translation of such technology is dependent on tailorable properties such as gravimetric changes in degradation environments. For SMPs synthesized from amino-alcohols, oxidation resulting in rapid mass loss may be problematic in terms of loss of material functionality as well as toxicity and cytocompatibility concerns. Control of gravimetric changes was achieved through the incorporation of small molecule antioxidants, either directly into the polymer matrix or included in microparticles to form a SMP composite material. Direct incorporation of small molecule antioxidants, such as phenolic alcohols, was found to alter shape memory attributes and increase elastic modulus at the expense of the strain to failure. Such changes could not ensure retention of the antioxidants and therefore did not increase oxidative stability. However, the inclusion of antioxidants in microparticles was found to produce materials with similar thermomechanical and shape memory properties while increasing oxidative resistance compared to controls. The microparticle composite SMPs also act as a platform for environmental sensing, such as $\mathrm{pH}$-dependent fluorescence shifts and payload release, as demonstrated by fluorescent dyes and the release of antioxidants. The use of polyurethane-urea microparticles in porous SMPs is demonstrated to increase biostability of the materials, by approximately $25 \%$, and ultimately extend their lifespan for use in aneurysm occlusion as determined through calculated in vivo degradation rates corresponding to a porcine aneurysm environment.
\end{abstract}

Keywords: Shape memory polymer, oxidative degradation, microparticle, antioxidant, composite

\section{Introduction}

The degradation of polyurethanes used in medical applications has been known for decades, with the original formulations undergoing hydrolysis of ester bonds in chain extending soft segments, and subsequent formulations suffering from either hydrolysis or oxidation of alternative linkages, such as carbonates or ethers, respectively. ${ }^{1-2}$ The carbamate linkage may eventually undergo hydrolysis, resulting in amine formation that is considered a carcinogen risk in the case of aromatic amines, although the actual risk from this is still not certain and the polyurethane species are widely utilized. ${ }^{3-5}$ Degradation in polyurethane medical devices is still of great concern, either for medical functionality or to reduce regulatory risk associated with degradable materials and possible toxicity. ${ }^{1-2}$ 
One example, specific to porous polyurethane materials, is the polyurethane foam breast implants in which toxicity concerns have been associated with foam erosion in implantable biomaterials that was linked to toluene diamine. ${ }^{3-5}$ Sokolowski et al. developed a porous shape memory polyurethane (SMP) for cerebrovascular aneurysm occlusion based on the Mitsubishi thermoplastic SMP formulations. ${ }^{6-7}$ Wilson et al. developed an alternative SMP system that utilized aliphatic diisocyanates and multifunctional amino-alcohols as crosslinkers to produce a thermoset polymer with crosslinks possessing molecular weighs below $700 \mathrm{Da}{ }^{8}$ These thermosets were intended to possess high shape memory strain recovery and minimal stress recovery, to leverage these materials for cardiovascular applications where wall stresses could compromise material functionality. ${ }^{8}$ Previous work on these materials demonstrated biocompatibility and functionality in aneurysm occlusion; however, degradation studies found rapid gravimetric changes as a result of amine oxidation, with end products including aldehydes, lower amines, and oxalic acid, which can lead to renal failure at sufficient concentrations. ${ }^{9-11}$ While degradable materials are suitable for many applications, the rapid release of degradation products presents significant risks for cerebrovascular aneurysms application, which may cause health concerns from a regulatory perspective, due to the proximity of the material to the brain. ${ }^{12}$ Tuning the rate of mass loss through control of biostability is an important method of reducing regulatory risk, and incorporation of antioxidants has previously been used to extend biostability in polymeric medical devices. $^{1,13}$

A goal of this work was to minimize matrix changes to retain biocompatibility of the SMP by forming SMP composites by incorporating polymeric particles with antioxidants. Compositing offers the opportunity to incorporate multiple functionalities simultaneously, such as mechanical and visualization. Previous work with metal and metal oxide composite SMPs resulted in enhanced imaging visibility in select cases, in addition to thermo-mechanical property changes, based upon loading thresholds migration as a function of additive concentration, which also altered SMP foam stability during synthesis by compromising pore integrity. ${ }^{14-16}$ The use of polymeric particles was hypothesized to reduce property migration while allowing for incorporating antioxidants to control degradation or release as drug analogs.

Particle systems have been proposed and tested for a variety of fields. In medical applications, microparticles have been proposed for drug releasing systems, chemical sensors, and visualization. ${ }^{17-21}$ A series of antioxidant microparticles, synthesized from a hydrolytically degradable vanillyl alcohol-containing copolyoxalate, was synthesized and tested in conjunction with dexamethasone. ${ }^{22-23}$ However, these particles would release $c a 80 \%$ of the drug payload within 12 hours, and had sizes ranging from $c a 10-15 \mu \mathrm{m} .{ }^{24}$ While the authors did not examine the degradation products, this polymer will also degrade into the potentially toxic oxalic acid. ${ }^{25}$ The same particles were previously studied for their interaction with hydrogen peroxide $\left(\mathrm{H}_{2} \mathrm{O}_{2}\right)$ as radical scavengers. ${ }^{25}$ Polyketal microparticles were tested for radical scavenging by delivering superoxide dismutase to a model of lung fibrosis, with the ketals displaying no inflammation response compared with the inflammation found using the standard poly(lactic-co-glycolic acid) (PLGA) particles, and ultimately inhibiting lung fibrosis. ${ }^{25}$ Formation of porous polyurethane microspheres through solution templating, using calcium carbonate solution, has been attempted, resulting in particles with $c a 7.5 \mu \mathrm{m}$ diameters. ${ }^{26-28}$ A solution of dimethyl sulfoxide (DMSO) and water $\left(\mathrm{H}_{2} \mathrm{O}\right)$ was used to produce porous polyurethane microparticles in a one-pot reaction that included the use of polyvinyl alcohol and isophorone diisocyanate. ${ }^{29}$ Castor oil and methylene-diphenyl diisocyanate were reacted to form thermoplastic polyurethane microparticles, with water added to produce the polyurea. ${ }^{30}$ Acetone/water mixtures have been used with a variety of amines 
to produce polyurea microspheres and particles with a range of sizes. A modification of this method, to yield poly(urethane urea) shell particles, was selected in this study due to the similarities with matrix composition as well as the well understood degradation products from particle degradation. ${ }^{11,31}$

Numerous antioxidant systems have been studied in polymer systems, including hindered amine light scavengers (HALS), phenol and phenol-derivatives, and phosphites in polyurethane systems across numerous applications, including biomedical materials, although rarely for specifically increasing biostability as determined through gravimetric analysis. ${ }^{32-34}$ Butylated hydroxytoluene (BHT) has been used successfully in polyethylene and its derivatives, with specific applications in medicine and medical materials such as improving oxidative damage that occurs during sterilization of total joint replacement polymeric implants. ${ }^{34}$ These antioxidants may scavenge the radicals that preferentially attack the tertiary amines, thus reducing mass loss of the SMP. However, direct utilization of in-chain antioxidants or antioxidant degradation products requires the initial polymer chain degradation that may compromise the bulk integrity of the polymer. This can be avoided by incorporating antioxidants into the abovementioned SMP composites.

Here we present a method for producing hollow poly(urethane urea) microparticles with average diameters ranging from 2 to $10 \mu \mathrm{m}$. Particles were synthesized with or loaded with antioxidants prior to incorporation into SMPs. Characterization of these materials indicates that this method for including antioxidants is superior to the direct incorporation of small molecule antioxidants, as the composites do not display significant thermo-mechanical property changes or shape recovery kinetic differences. Additionally, the SMP composites were also demonstrated as a platform for continuous release and degradation environment detection as proof of concept for expanded material functionalities.

\section{Methods and Materials}

Materials: Materials were purchased from Sigma-Aldrich and used without modification unless otherwise stated. Hexamethylene diisocyanate (98\%, HDI), isophorone diisocyanate (98\%, IPDI), triethanolamine (99\%, TEA), N,N,N',N' tetrakis (hydroxypropyl) ethylenediamine (98\%, HPED), diethanolamine (99\%, DEA), butylated hydroxytoluene (BHT), 1,2,2,6,6 tetramethyl piperidinol (piper), and 2,2'-methylenebis(6-tert-butyl-methylphenol (methyl) (SI Figure 1), Phloxine B (PhB) and Nile blue chloride (Nile) were used as monomers. Ethanol $(97 \%, \mathrm{EtOH})$ and isopropyl alcohol (99.5\%) were used as solvents for cleaning the materials after synthesis and degradation testing, respectively. Cobalt chloride $\left(\mathrm{CoCl}_{2}\right)$ and hydrogen peroxide $\left(\mathrm{H}_{2} \mathrm{O}_{2}, 50 \%\right)$ were used for degradation analysis. Ethyl isocyanate (98\%) was used for model reactions. Acetonitrile (99.93\%, HPLC grade), methanol $\left(50 \%\right.$ in $\mathrm{H}_{2} 0$ with $0.1 \% \mathrm{v} / \mathrm{v}$ formic acid, LCMS grade), methanol (99.9\%, LCMS grade), and water solution ( $0.5 \% \mathrm{v} / \mathrm{v}$ formic acid, HPLC grade) were used with liquid chromatography.

General: Fourier transform infrared spectroscopy (FTIR) attenuated total reflectance (ATR) was performed using a Bruker ALPHA infrared spectrometer (Bruker, Billerica, MA); 48 scans per spectra for both background and samples were used. Spectra data were collected in absorption mode with a resolution of $4 \mathrm{~cm}^{-1}$. OPUS ${ }^{\text {TM }}$ software was used to examine spectra, identify peaks, and perform baseline and atmospheric corrections. Spectral data collection was performed in triplicate to confirm results. X-ray photoelectron spectroscopy (XPS) (Omicron ${ }^{\mathrm{TM}}$ XPS with Argus detector) using a $\mathrm{Mg} / \mathrm{Al} \mathrm{x}$-ray source was used to characterize particles and SMPs. 
Gas chromatography mass spectrometry (GCMS, positive mode) was used to determine the extracted concentration using a Thermo Scientific ${ }^{\text {TM }}$ DSQ II Series Single Quadrupole GCMS (ThermoFisher Scientific, Waltham, MA), as well as the degradation products from the model compounds. A $10 \mathrm{uL}$ sample volume was injected, with a dwell time of 4 seconds. The initial temperature was $50^{\circ} \mathrm{C}$, heated to $320^{\circ} \mathrm{C}$ at a rate of $20^{\circ} \mathrm{C} / \mathrm{min}$. The flow rate was $50 \mathrm{~mL} / \mathrm{min}$ with a surge pressure of 0.44 psi using methanol.

Product determination was confirmed using liquid chromatography mass spectrometry (LCMS). Samples were diluted 100-fold in a 50\% methanol (49.95\% water, $0.05 \%$ formic acid) solution, and injected into a normal phase $\mathrm{C} 18$ silica column. The injection volume was $10 \mu \mathrm{L}$, and the mass flow rate was varied from $0 \%$ acetonitrile to $95 \%$ acetonitrile over a 6 -minute gradient. An Exactive Plus OrbiTrap Mass Spectrometer (ThermoFisher Scientific, Waltham, MA) was used to perform MS. The capillary temperature was $100^{\circ} \mathrm{C}$. Spectral data were collected over a 30second integration and Xactive ${ }^{\mathrm{TM}}$ software (ThermoFisher Scientific, Waltham, MA) was used for analysis.

Microparticle Synthesis: Microparticle synthesis was achieved using a modified procedure previously reported by Kong et al. ${ }^{31}$ In short, IPDI ( $\left.5 \mathrm{~g}, 22.5 \mathrm{mmol}\right)$ was added to a water/acetone solution (95 g) and mixed for 1 hour at room temperature. Reaction temperature and solvent ratio were varied to optimize synthetic outcomes. TEA (29.97 mmol), DEA, or HPED were dissolved, while stirring at $30 \mathrm{rpm}$, in the mixture. $5 \mathrm{~g}$ IPDI $(22.5 \mathrm{mmol})$ was added over 10 minutes at a constant rate. The reaction was allowed to proceed overnight, yielding a viscous white solution. The solution was centrifuged for $5 \mathrm{~min}$ at $4000 \mathrm{rpm}$, and the particles were rinsed in $\mathrm{H}_{2} \mathrm{O}$-acetone (30/70 ratio) three times before drying at $70^{\circ} \mathrm{C}$ overnight. Particles were dried and characterized (yield 54\%).

Microparticle Extraction and Loading: The thermoplastic core was extracted using IPA/acetone mixtures at $50^{\circ} \mathrm{C}$ for 12 hours with a one-hour sonication (solution was changed every 4 hours). ${ }^{31}$ Particles were then centrifuged and separated from the effluent, and removal of the core was confirmed using differential scanning calorimetry and x-ray diffraction experiments. Loading of the particles was performed by dissolving $20 \mathrm{~g}$ of antioxidant or fluorescent dye into solution and adding $20 \mathrm{~g}$ of particles. The mixture was stirred and heated to $50^{\circ} \mathrm{C}$ overnight. Particle solutions were then centrifuged, separated, washed three times using $\mathrm{H}_{2} \mathrm{O}$ /acetone, and dried overnight at $50^{\circ} \mathrm{C}$, to produce loaded microparticles (i.e. BHT-L). Synthesis of antioxidant-containing particles was repeated with $50 \%$ wt of antioxidants added immediately after the alcohol, prior to the additional IPDI. Particles were collected and washed the same way as described previously. Particles synthesized in this way are labeled Synth (i.e. BHT-S). A general schematic for synthesis is presented in Figure 1.

Shape Memory Polymer Synthesis: Porous SMP scaffolds were synthesized using a traditional two-step polyurethane foam synthesis process. ${ }^{35}$ An isocyanate (NCO) premix was first made by adding $40 \%$ of the desired alcohols (molar \% of total alcohols used; the exact percentage could be varied to control premix viscosity and thus scaffold pore size) to the entire amount of diisocyanate, with a ratio of $\mathrm{NCO}: \mathrm{OH}$ of $\mathrm{ca} 2: 1 .^{35}$ This premix was cured at $50^{\circ} \mathrm{C}$ for 36 hours. The alcohol $(\mathrm{OH})$ premix was then synthesized, consisting of the remaining alcohols, antioxidants or particles ( 5 and $10 \% \mathrm{wt}$ ), surfactants, catalysts, water, and a physical blowing agent. ${ }^{35}$ The $\mathrm{OH}$ premix was combined with the isocyanate premix along with microparticles, using a high-speed shear mixer, 
followed by the addition of a physical blowing agent. The scaffold was cured at $90^{\circ} \mathrm{C}$ for 20 minutes, followed by cold curing overnight at ambient conditions.

Light Microscopy, Confocal Microscopy, and Scanning Electron Microscopy (SEM): SMP samples were cut to less than $1 \mathrm{~mm}$ thickness for microscopy. Using previously described methods, particles were characterized using light microscopy. ${ }^{35}$ SMP samples were imaged using an Olympus ${ }^{\mathrm{TM}}$ Fluoview 1000 laser scanning confocal microscope (LSCM) (Olympus America Inc, Center Valley, PA), and were excited at $543 \mathrm{~nm}$ utilizing less than $1 \%$ maximum intensity. ${ }^{14}$ Foam cell structure was determined by cutting axial and transverse samples that were examined using SEM. Samples were mounted on a stage and sputter coated with gold using a Cressington Sputter Coater (Ted Pella, Inc., Redding, CA) for 60 seconds at $20 \mathrm{~mA}$. Samples were then examined using a Joel NeoScope JCM-5000 SEM (Nikon Instruments Inc., Melville, NY).

Thermal Analysis: Differential scanning calorimetry (DSC) was also used to measure both wet and dry $\mathrm{T}_{\mathrm{g}}$ using a Q-200 DSC (TA Instruments, Inc., New Castle, DE). Samples of $c a(5.0 \pm 1.0) \mathrm{mg}$ were sealed in TZero ${ }^{\mathrm{TM}}$ aluminum pans and placed in the heating cell. Dry samples were cooled to equilibration at $-40^{\circ} \mathrm{C}$, heated to $120^{\circ} \mathrm{C}$ at $10^{\circ} \mathrm{C} / \mathrm{min}$, cooled at $10^{\circ} \mathrm{C} / \mathrm{min}$ to $-40{ }^{\circ} \mathrm{C}$ and heated to $120^{\circ} \mathrm{C}$ at $10^{\circ} \mathrm{C} / \mathrm{min}$. The half-height transition of the final heating cycle was the reported $\mathrm{Tg}$. Wet samples were weighed and sealed in the same manner, and were then heated from $-40^{\circ} \mathrm{C}$ to $80^{\circ} \mathrm{C}$ at $10^{\circ} \mathrm{C} / \mathrm{min}$.

Thermogravimetric analysis (TGA) was used to assess any changes in thermal degradation temperatures. A TA Q50 TGA (TA Instruments, New Castle, DE) was used to heat samples to $500^{\circ} \mathrm{C}$ at $10^{\circ} \mathrm{C} / \mathrm{min}$ under a mixed atmosphere of oxygen and nitrogen $(60 \mathrm{~mL} / \mathrm{min}$ to $40 \mathrm{~mL} / \mathrm{min}$ respectively). Samples were examined for the onset of degradation temperature and major transitions in the mass loss profiles

Shape Memory Characterization: Shape recovery of cylindrical foam samples (6 $\mathrm{mm}$ diameter, 10 $\mathrm{mm}$ length, six samples per series) crimped over a wire was examined at $50{ }^{\circ} \mathrm{C}$ in reverse osmosis (RO) water to determine the volume recovery behavior (strain recovery) ${ }^{14}$ Samples were crimped to a minimal diameter $(\mathrm{ca} 1.0 \mathrm{~mm}$ ) using a SC150-42 Stent Crimper (Machine Solutions, Flagstaff, AZ). For radial compression, samples were equilibrated at $100^{\circ} \mathrm{C}$ for ten minutes and then radially compressed and cooled to room temperature. Samples relaxed for 12 hours and were tested over the course of 30 minutes. Image ${ }^{\mathrm{TM}}$ was used for analysis of the change in diameters over time.

Mechanical Testing: Uniaxial tensile testing was performed on ASTM d638 IV samples using an Instron Tensile Tester with $500 \mathrm{~N}$ load cell. The extension rate was set to $5 \mathrm{~mm} / \mathrm{min}$ at room temperature. Seven samples were tested for each species. Elastic modulus, strain to failure, and ultimate tensile strength were calculated.

Fluorescence: Fluorescence wavelengths were examined using a Fluoromax Fluorometer (Horiba UK Limited, Middlesex, UK). Selected excitation wavelengths were determined from the literature and confirmed by excitation scans; $\mathrm{PhB}$ was excited with approximately $515 \mathrm{~nm}$; Nile was excited at $635 \mathrm{~nm}$.

Payload Release: Release of antioxidants was studied using $2.0 \mathrm{~g}$ SMPs in $50 \mathrm{~mL}$ of IPA at $37^{\circ} \mathrm{C}$. Samples were withdrawn and the solution was examined using GCMS. The solution was injected 
into the column (C18 silica, normal phase) and heated at $20{ }^{\circ} \mathrm{C} / \mathrm{min}$ to $300{ }^{\circ} \mathrm{C}$. UV-vis was used to confirm release rates.

Degradation Analysis: Previously, the rate of degradation for control compositions was determined for porcine aneurysm conditions and related to the rate of degradation as demonstrated using accelerated oxidative solution $\left(20 \% \mathrm{H}_{2} \mathrm{O}_{2}\right.$ with $0.1 \mathrm{M} \mathrm{CoCl}_{2}$ at $\left.37{ }^{\circ} \mathrm{C}\right) .{ }^{11} \mathrm{~A}$ uniformly applied acceleration factor of 57.14 was found to model the real time degradation of the controls. Pore size and interconnectivity, and strut thickness were assumed to be identical and therefore were neglected.

\section{Results and Discussions}

\section{Microparticle Synthesis}

Synthetic conditions were varied by changing solvent ratio, temperature, and alcohol species in solution with IPDI. The size of the particles obtained with the three amino alcohols (HPED, TEA, DEA) was characterized using SEM (SI Figure 2-11), with quantified metrics shown in Table 1. TEA was selected for further examination due to particle size and distribution, as well as the suspected less hydrophilic network and more rapid release/degradation rates previously demonstrated in non-composite porous SMPs. ${ }^{11}$ While the smallest size distribution was achieved with HPED $\left(\boldsymbol{D}_{\boldsymbol{w}} / \boldsymbol{D}_{\boldsymbol{n}}=1.10\right)$, TEA at room temperature resulted in the smallest particle diameter, similar to those results reported by Kong and others using similar methods. ${ }^{31,36}$ Results obtained by changing the temperature indicated that room temperature gave the smallest particle diameter of $2.43 \pm 0.91 \mu \mathrm{m}$, a size that falls within the desired range for embolic applications and for particles that can be phagocytized by cells. ${ }^{37-38}$

Poly(urethane) urea (PU) microparticles contain a thermoplastic polyurea core with the poly(urethane urea) crosslinked shell surrounding it. Removal of the core was achieved through sonication in solvent and confirmed using DSC and XRD (Figure 2), with the thermoplastic polyurea core displaying semi-crystalline behavior as determined by a peak at $33.843^{\circ}$ by XRD (lattice spacing of $5.47 \AA$ by Bragg equation) and a melting peak at $c a 170^{\circ} \mathrm{C}$, both of which are not present in the crosslinked shell after extraction. After core removal, the particles were loaded with the antioxidants or the fluorescent molecules. Loading during synthesis was viable only for BHT and Piper, as Methyl is not soluble in the polymer solution sufficiently. Loading percentages of up to $45 \%$ were attempted during synthesis and did not appear to alter particle composition or morphology, but the removal of BHT was a possibility during particle cleaning and so was not further examined. Loadings of $c a 45 \%$ (wt) were achieved using physical means after synthesis. 


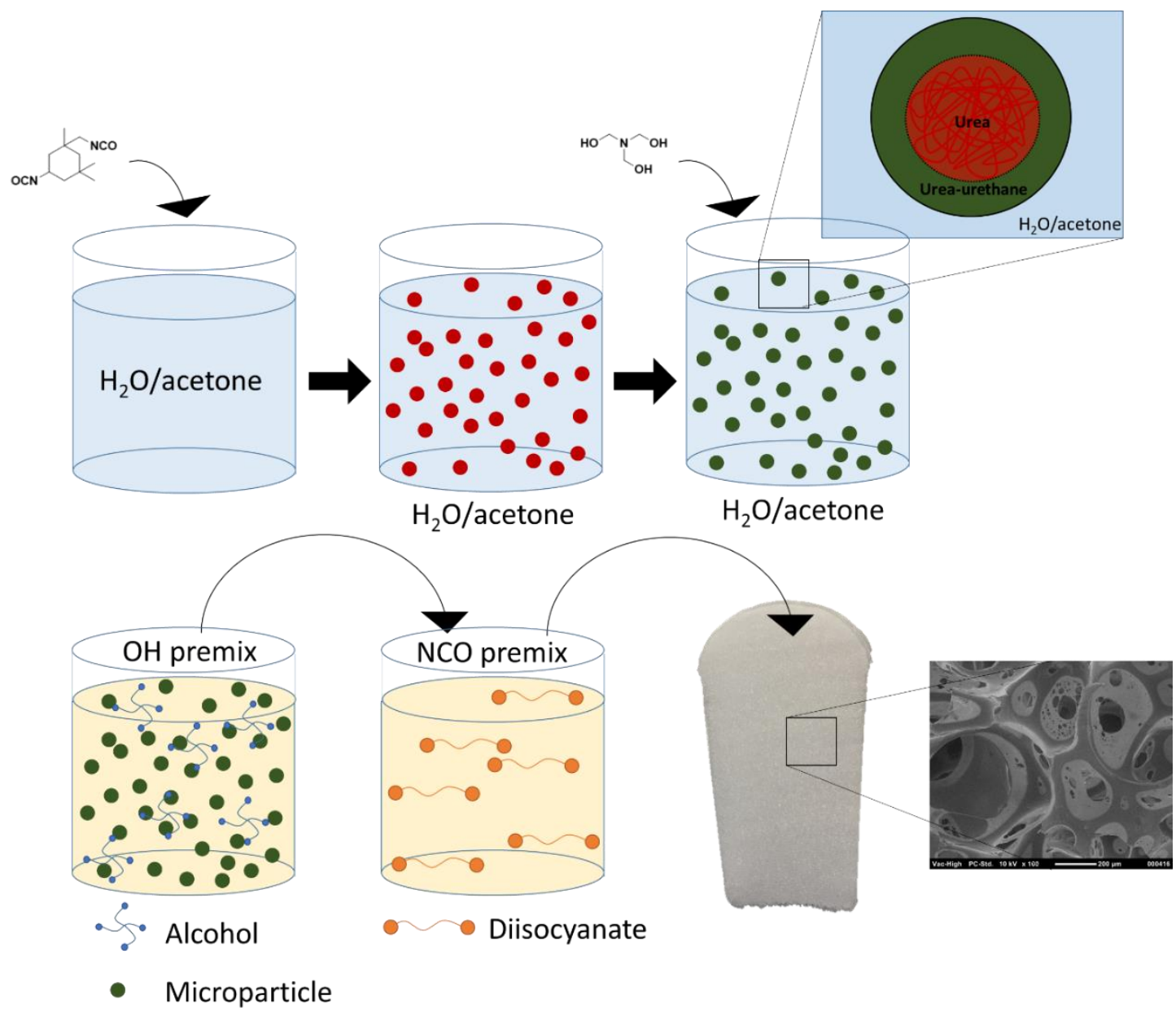

Figure 1. A general overview of synthetic process, illustrating the microparticle synthesis in acetone/water, extraction of the particle core with the addition of antioxidants, and the synthesis of SMP foam using a two-step foaming method including the microparticles, which can be substituted for small molecule antioxidants.
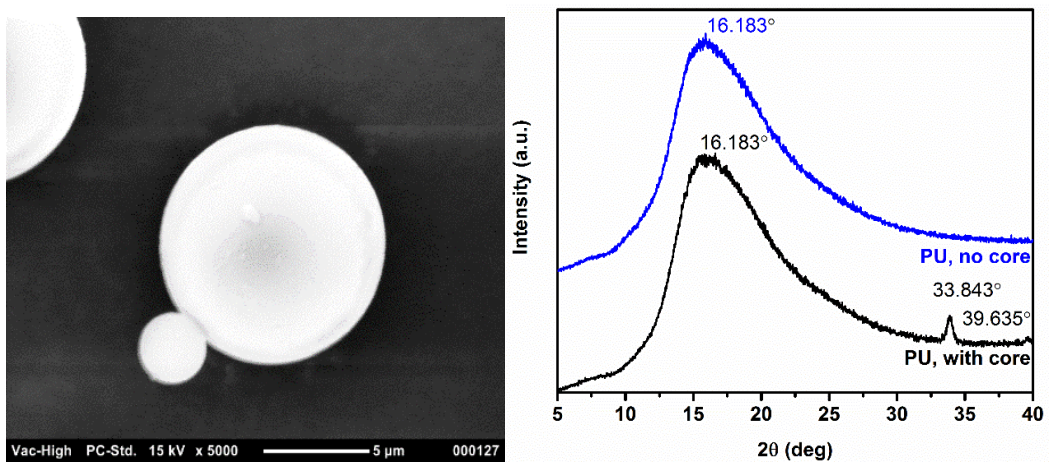

Figure 2. Scanning electron microscopy and XRD comparison of the areas of the original microspheres (PU with core) and those that have undergone extraction reveals a relative crystallinity of $3.3 \%$ for the starting material, which can be attributed to the thermoplastic polyurea core. 
Table 1. Impact of synthetic methods on average particle diameter and distribution.

\begin{tabular}{|c|c|c|c|c|c|c|}
\hline \% acetone & \% water & $\begin{array}{c}\text { Temperature } \\
\left({ }^{\circ} \mathrm{C}\right)\end{array}$ & Monomer & $\begin{array}{c}\text { Number ave } \\
\text { Distribution } \\
\text { Diameter } \\
\left(D_{n}\right)(\mu \mathrm{m})\end{array}$ & $\begin{array}{c}\text { Weight ave } \\
\text { Distribution } \\
\text { Diameter } \\
\left(D_{w}\right)(\mu \mathrm{m})\end{array}$ & $D_{w} / D_{n}$ \\
\hline 70 & 30 & $50^{\circ}$ & TEA & 6.79 & 10.69 & 1.57 \\
\hline 70 & 30 & $50^{\circ}$ & DEA & 7.25 & 8.74 & 1.29 \\
\hline 70 & 30 & $50^{\circ}$ & HPED & 9.54 & 10.48 & 1.10 \\
\hline 70 & 30 & $0^{\circ} \mathrm{C}$ & TEA & 6.66 & 9.12 & 1.37 \\
\hline 70 & 30 & $20^{\circ} \mathrm{C}$ & TEA & 2.80 & 4.18 & 1.49 \\
\hline 70 & 30 & $80^{\circ} \mathrm{C}$ & TEA & 6.42 & 9.12 & 1.42 \\
\hline 30 & 70 & $20^{\circ}$ & TEA & 6.66 & 9.72 & 1.46 \\
\hline 50 & 50 & $20^{\circ}$ & TEA & 4.53 & 7.05 & 1.56 \\
\hline 60 & 40 & $20^{\circ}$ & TEA & 4.69 & 8.29 & 1.77 \\
\hline
\end{tabular}

\section{Composite SMPs Synthesis}

The spectra of the SMP foams (Figure 3) displayed the characteristic polyurethane bands including hydroxyl bands at $3250-3500 \mathrm{~cm}^{-1}$, the methyl band at $2800-3000 \mathrm{~cm}^{-1}$, the carbonyl peak at $1688 \mathrm{~cm}^{-1}$ that denotes the urethane bond and the corresponding shoulder for the urea bond at $c a 1640 \mathrm{~cm}^{-1}$, and the skeletal carbon peak at $1252 \mathrm{~cm}^{-1}{ }^{39}$ The lower wavenumbers for the urethane peak are due to the increased hydrogen bonding achieved using aliphatic monomers as well as the high urea content in the composition (due to water added during the foam blowing synthesis). ${ }^{11}$ The Methyl and Thio SMPs display shoulders on the carbonyl at $c a 1710-1730 \mathrm{~cm}^{-1}$ that correspond to the ester bonds in the antioxidants (Thio) or the formation of a new urethane linkage (Methyl) (SI Figure 12). The increase in the relative height of the urethane carbonyl of the Piper SMP, compared with the control, indicates the formation of the urethane linkage. ${ }^{1} \mathrm{H},{ }^{13} \mathrm{C}$ NMR confirmed the formation of urethane linkages for Methyl and Piper antioxidants; other examined species contained original structures and small concentrations of urea linkages. Mass spectroscopy (SI Figure 12) supported these findings, indicating that Methyl could form monoand biurethane linkages, while Piper formed only a single urethane; BHT, Thio, and Triphen would only interact non-covalently.

XPS confirmed the incorporation of greater amounts of free hydroxyls $(286.4 \mathrm{eV})$ associated with the leftover end groups from the synthesis, as well as a shoulder peak at $288.7 \mathrm{eV}$ associated with carbonyls. ${ }^{28}$ No differences were found for antioxidants during loading, during synthesis, or post-synthesis (SI Figure 13). ${ }^{11}$ The residual presence of tin, a foaming catalyst, and silicone, from the surfactants used, were found in all SMPs. The dual binding peak seen for the $\mathrm{C} 1 \mathrm{~s}$ scan at $286.6 \mathrm{eV}$ may also indicate a greater presence of $\mathrm{C}-\mathrm{N}$ bonds as well as hydroxyls, as a result of greater incorporation of the alcohol into the SMP compared to the microparticle, which possesses a thermoplastic core and linear shell components (urea contributions). This is supported by the relative area of the N1s peak displayed for the SMP compared with the particles in the 
survey scan. Additionally, the shoulder peak in the $\mathrm{C} 1 \mathrm{~s}$ scan centered at $286.06 \mathrm{eV}$ indicates a greater concentration of free alcohols, which is expected stoichiometrically from the preferential consumption of the isocyanates to form the urea, followed by urethane, then branching reactions due to synthetic conditions (SI Figure 13-15). The consistent shoulder at ca $288.5 \mathrm{eV}$, indicative of the carbonyls, is expected based on the urethane-urea nature of the materials. The qualitative decrease in peak strength for the SMPs may be due to the decrease in relative concentration of the urea/urethane carbonyl relative to the backbone.

For the particles themselves, the $\mathrm{Cl} 2 \mathrm{~s}$ and $\mathrm{Br} 3 \mathrm{p}$ peaks associated with $\mathrm{PhB}$ were found as fairly weak signals, indicating that the dye was not just on the surface of the particles but contained within the shell as well. The decreased O1s peak for the particles may be attributed to residual urea in the polymer shell compared to a urethane linkage, which may also explain the shoulders found in the C1s scans as explained above. The dye particles did not display any changes in the N1s peak, which was anticipated. The antioxidant-containing particles displayed the same shoulder at $286.6 \mathrm{eV}$ as that of the other particles, but is again not found in the SMP composites, providing further support for this being a urea carbonyl peak. Most importantly for these particles, the O1s peak $(531.7 \mathrm{eV})$ was found to be broader for the particles where antioxidants were loaded in after synthesis, compared to particles where the antioxidants were included during synthesis. For example, the Piper synth peak is sharp and centered at $c a 531 \mathrm{eV}$, whereas Piper load is broader with a distinctive shoulder closer to $c a 532.5 \mathrm{eV}$, a trend which is repeated in the BHT particles.
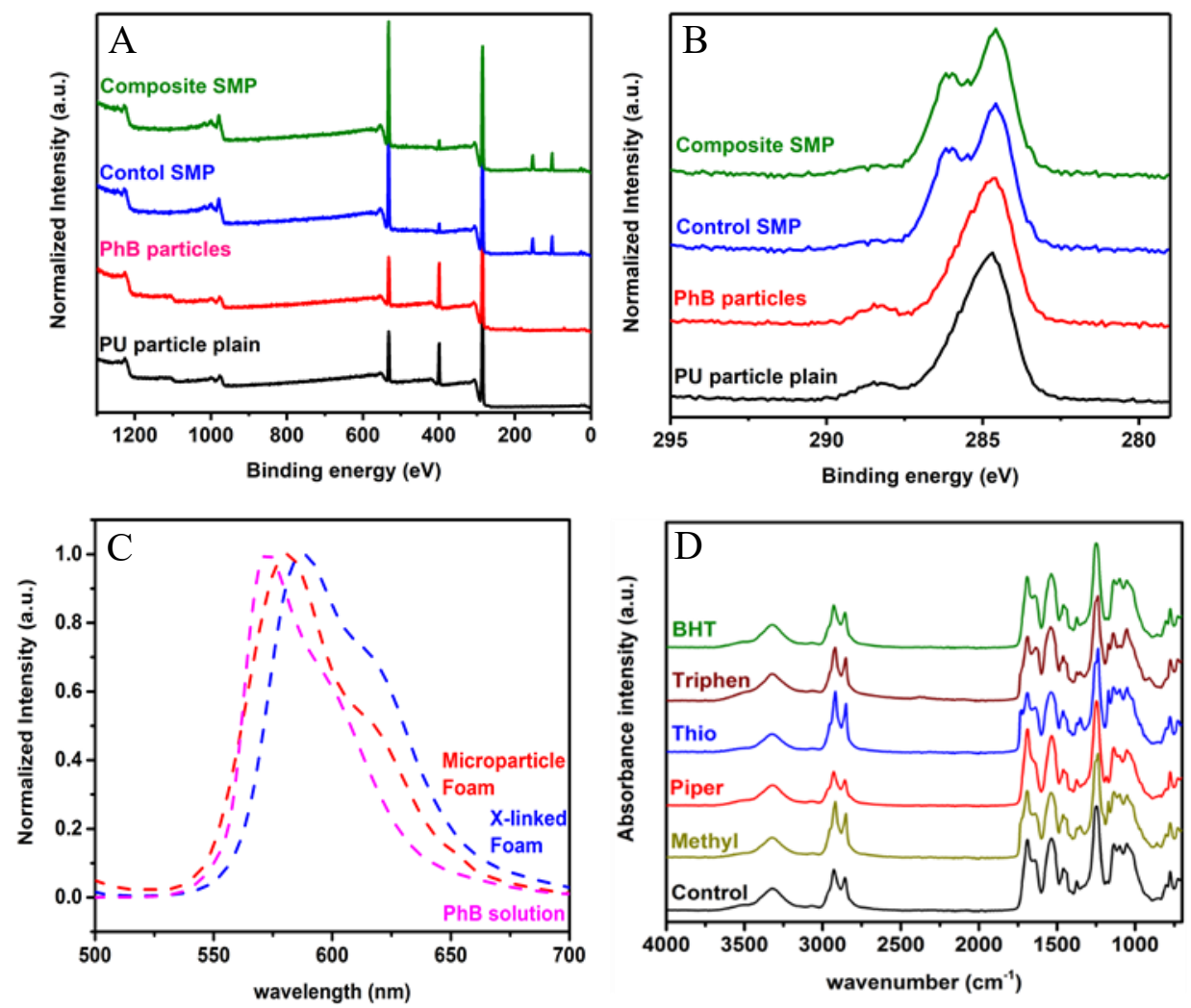

Figure 3. Spectroscopic characterization of poly(urethane urea) microparticles and SMP foams. XPS comparison of survey scan (A) and C1s scan (B) demonstrates the greater incorporation of amines from amino alcohols $(\mathrm{C} 1 \mathrm{~s}$ peak at $\sim 286 \mathrm{eV})$ and the presence of silicone from surfactants (survey scan below $200 \mathrm{eV}$ ). Fluorescence profiles, displaying minimal wavelength shift, that 
corresponds more closely to uncrosslinked phloxine, compared with previous studies utilizing crosslinked phloxine in SMP foams (C), and the shift in the carbonyl peak indicative of linkages other than the carbamate/urea peaks due to small molecules added to the SMP (D).

Fluorescence spectroscopy of SMP composites with PhB-containing particles was compared with SMPs doped with $\mathrm{PhB}$ and $\mathrm{PhB}$ in solution; emission spectra display a red-shift as a result of crosslinking and formation of a urethane linkage for $\mathrm{PhB}$. The emission spectra peak for $\mathrm{PhB}$ in solution ( $1 \mathrm{mM}$ in $\mathrm{H}_{2} \mathrm{O}$ ) was found to be $573 \mathrm{~nm}, 580 \mathrm{~nm}$ for the SMP composite, and $589 \mathrm{~nm}$ for the crosslinked $\mathrm{PhB}$. This indicates that the $\mathrm{PhB}$, enclosed in the microparticles, retains the functionality of the fluorescent molecule and that the payload is in fact incorporated in the particle rather than on the surface, thus providing further support for the XPS analysis results.

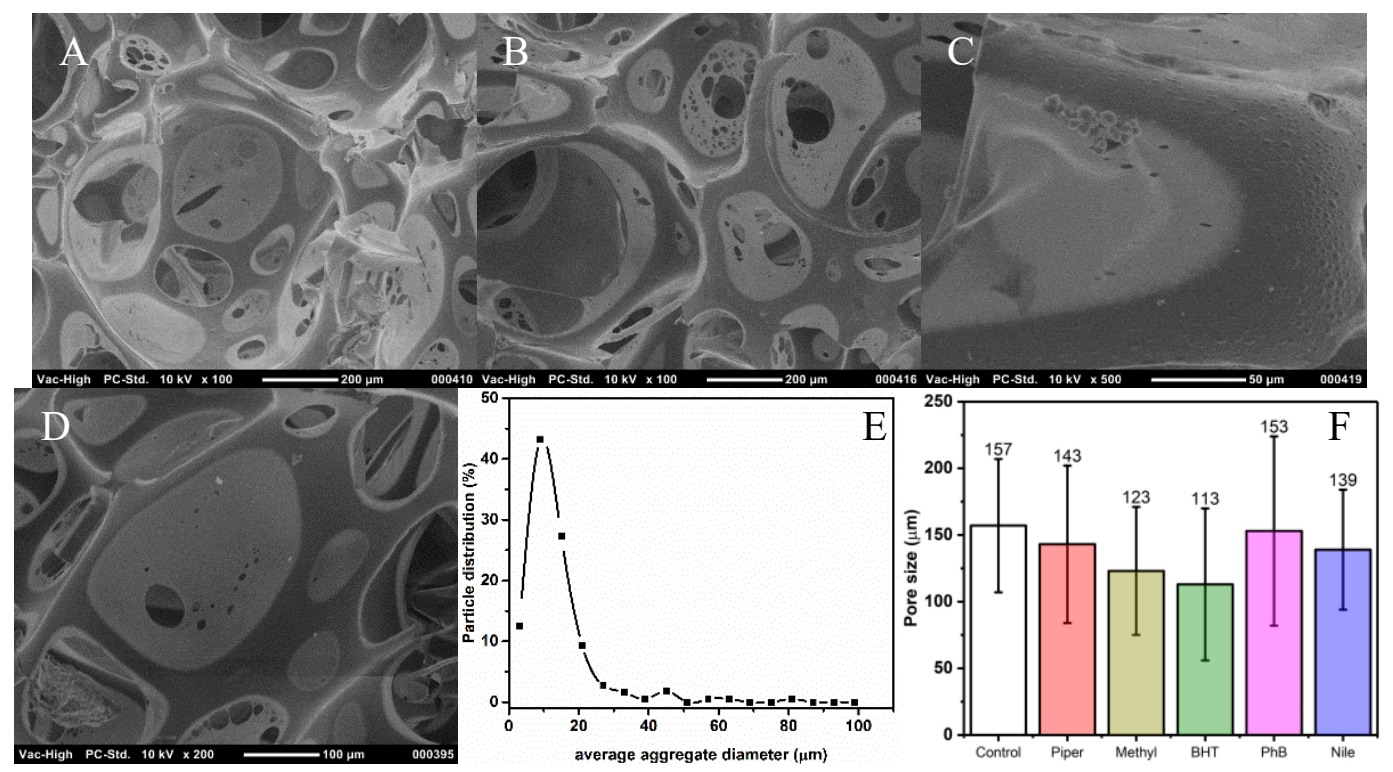

Figure 4. SMP foam with TEA- microparticles (control) (A), BHT-microparticles (B). The agglomeration of microparticles can be seen to occur along the edges of pore membranes (C, D). Aggregate diameters (E) and pore sizes (F) determined using microscopy.

The average strut diameter, determined from SEM, was $c a 20.7 \pm 3.6 \mu \mathrm{m}$. The average aggregate diameter was $13.4 \pm 10.1 \mu \mathrm{m}$, as displayed in Figure 4. It was determined through optical microscopy of fluorescent $\mathrm{PhB}$ particles, but aggregates were visible during SEM analysis as well; aggregate diameter seemed to be independent of composition. Qualitatively, pore membranes were found to be primarily intact with only pinholes between pores, with triangular struts throughout. Pore sizes were found to be consistent with the composite SMPs, with no statistical variation between species of the antioxidant or fluorescent molecule; qualitative evaluation of antioxidants, directly incorporated into the SMP foams, indicated a variation in foam cell formation resulting in widely variable pores, membranes, and bulk foam morphology. Antioxidant or dye species did not seem to impact pore morphology when included in microparticles (SI Figure 16-17).

\section{Thermomechanical Characterization}


Tensile testing comparisons revealed minimal differences between the microparticlecontaining SMPs. However, SMPs with antioxidants directly incorporated into them were found to have widely varied mechanical behaviors (Table 2, Figure 5). For small molecule antioxidant additives, an initial analysis was performed using HDI-based foams (SI Table 1) before being repeated using TMHDI-based materials, with trends reproducible for both formulations. Methyl again displayed enhanced properties relative to the control and the other examined species. The elastic modulus of the control was $1.45 \mathrm{MPa}$, while that of Methyl was $2.32 \mathrm{MPa}$; strain to failure for the control was $45.2 \%$ while Methyl's was $32.2 \%$. Of the other examined small molecule antioxidants, all species displayed increased strain to failure and tensile strength, except for Triphen. The Triphen SMP displayed nearly twice the strain to failure $(71.0 \%)$, while also possessing reduced tensile strength (1.41 MPa compared to 1.64MPa for the control) and a lower elastic modulus ( $0.44 \mathrm{MPa}$ ). Microparticles do not change the mechanical properties significantly when compared with the control (no particles/additives) composition. The changes that are displayed are not statistically significant and may be attributable to the intrinsic variability in SMP foam morphology that is obtained through the foaming process.

Table 2. Mechanical properties of control SMPs and those containing small molecule antioxidants only as well as microparticles loaded with antioxidants $(n=7)$.

\begin{tabular}{|c|c|c|}
\hline Species & $\begin{array}{c}\text { Elastic Modulus } \\
(\mathrm{MPa})\end{array}$ & $\begin{array}{c}\text { Strain to Failure } \\
(\%)\end{array}$ \\
\hline Control SMP & $1.45 \pm \mathbf{0 . 1 9}$ & $\mathbf{4 5 . 2} \pm \mathbf{1 1 . 6}$ \\
\hline $\begin{array}{c}\text { SMP Composite with Piper } \\
\text { microparticles }\end{array}$ & $1.32 \pm \mathbf{0 . 2 6}$ & $\mathbf{5 2 . 9} \pm \mathbf{8 . 2}$ \\
\hline SMP with Piper small molecule additive & $1.41 \pm \mathbf{0 . 1 9}$ & $\mathbf{5 6 . 6} \pm \mathbf{5 . 2}$ \\
\hline $\begin{array}{c}\text { SMP Composite with Methyl } \\
\text { microparticles }\end{array}$ & $1.19 \pm \mathbf{0 . 1 8}$ & $\mathbf{6 1 . 2} \pm \mathbf{2 6 . 1}$ \\
\hline $\begin{array}{c}\text { SMP with Methyl small molecule } \\
\text { additive }\end{array}$ & $\mathbf{2 . 3 2} \pm \mathbf{0 . 4 4}$ & $\mathbf{3 2 . 2} \pm \mathbf{7 . 3}$ \\
\hline $\begin{array}{c}\text { SMP Composite with BHT } \\
\text { microparticles }\end{array}$ & $1.52 \pm \mathbf{0 . 2 9}$ & $\mathbf{5 1 . 2} \pm \mathbf{5 . 8}$ \\
\hline SMP with BHT small molecule additive & $1.40 \pm 0.32$ & $\mathbf{5 1 . 0} \pm 6.2$ \\
\hline
\end{tabular}


A
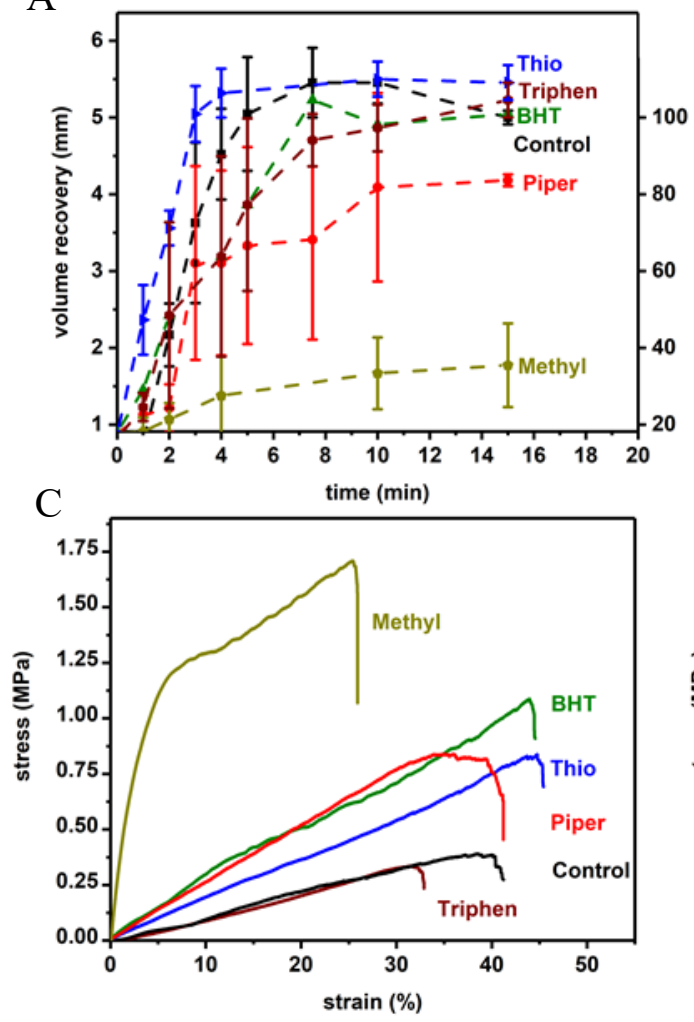

B
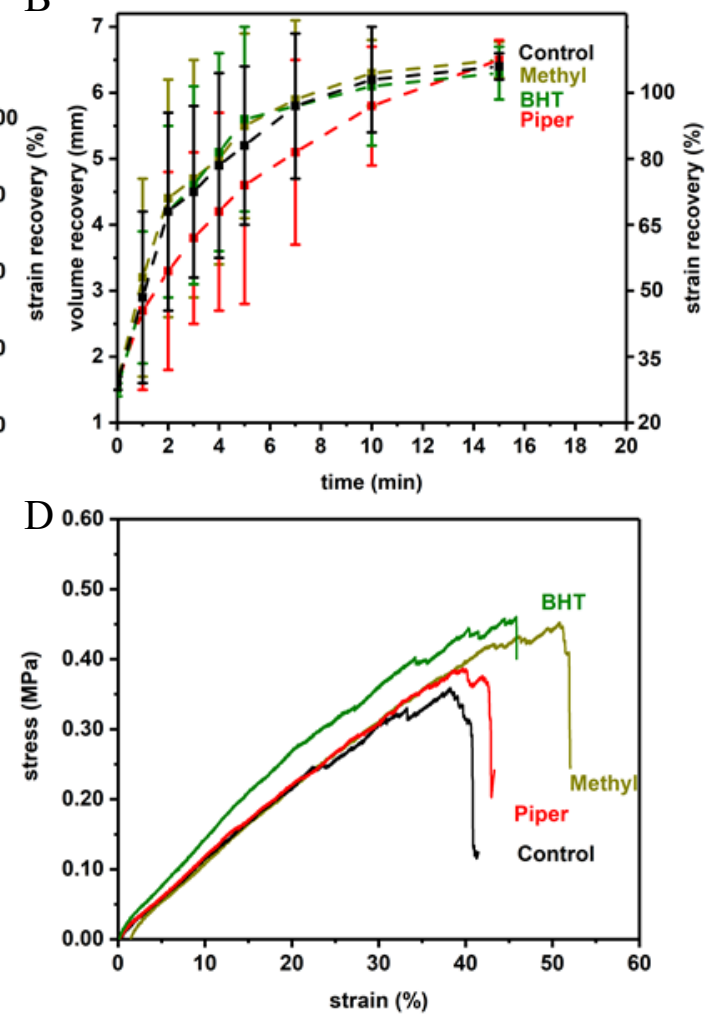

Figure 5. Shape memory behavior (both volumetric and strain recoveries) of porous SMPs with antioxidant small molecules $(10 \%, \mathrm{~A})$ and microparticles $(10 \%, \mathrm{~B})$ over 15 minutes in $37^{\circ} \mathrm{C} \mathrm{RO}$

$\mathrm{H}_{2} \mathrm{O}$; mechanical behavior (tensile) of SMPs with antioxidant small molecules $(10 \%, \mathrm{C})$ and microparticles $(10 \%, D)$.

Table 3. Thermal characterizations of antioxidant SMPs $(n=3)$.

\begin{tabular}{|c|c|c|c|c|c|}
\hline Species & $\mathbf{T}_{g}\left({ }^{\circ} \mathbf{C}\right)$ & Wet $\mathbf{T}_{\mathrm{g}}\left({ }^{\circ} \mathrm{C}\right)$ & $\mathbf{T}_{\mathrm{d}}$ (onset temp) $\left({ }^{\circ} \mathrm{C}\right)$ & $\mathrm{T}_{\mathrm{d}}$ (derivative peak) $\left({ }^{\circ} \mathrm{C}\right)$ & $\begin{array}{c}\text { Tm }\left({ }^{\circ} \mathrm{C}\right)(\text { Monomer melt } \\
\left.\text { transition, }{ }^{\circ} \mathrm{C}\right)\end{array}$ \\
\hline Control & $55.3 \pm 0.3$ & $10.4 \pm 1.0$ & $239 \pm 2$ & $273 \pm 3$ & - \\
\hline $\begin{array}{c}\text { SMP Composite } \\
\text { with Piper } \\
\text { microparticles }\end{array}$ & $55.5 \pm 0.4$ & $10.2 \pm .08$ & $251 \pm 1$ & $278 \pm 2$ & $-\quad(130)$ \\
\hline $\begin{array}{l}\text { SMP with Piper } \\
\text { small molecule } \\
\text { additive }\end{array}$ & $55.0 \pm 0.3$ & $11.5 \pm 1.1$ & $250 \pm 1$ & $279 \pm 1$ & - (130) \\
\hline $\begin{array}{l}\text { SMP Composite } \\
\text { with Methyl } \\
\text { microparticles }\end{array}$ & $55.6 \pm 0.2$ & $10.4 \pm 1.1$ & $258 \pm 1$ & $300 \pm 2$ & $-\quad(125)$ \\
\hline
\end{tabular}




\begin{tabular}{|c|c|c|c|c|c|}
\hline $\begin{array}{l}\text { SMP with Methyl } \\
\text { small molecule } \\
\text { additive }\end{array}$ & $61.5 \pm 0.2$ & $14.2 \pm 1.4$ & $260 \pm 3$ & $299 \pm 4$ & $-\quad(125)$ \\
\hline $\begin{array}{c}\text { SMP Composite } \\
\text { with BHT } \\
\text { microparticles }\end{array}$ & $55.3 \pm 1.0$ & $10.5 \pm 0.7$ & $261 \pm 3$ & $301 \pm 2$ & $-\quad(71)$ \\
\hline $\begin{array}{l}\text { SMP with BHT } \\
\text { small molecule } \\
\text { additive }\end{array}$ & $57.2 \pm 0.8$ & $10.2 \pm 1.9$ & $261 \pm 1$ & $303 \pm 2$ & $-\quad(70)$ \\
\hline $\begin{array}{l}\text { SMP with Thio } \\
\text { small molecule } \\
\text { additive }\end{array}$ & $41.0 \pm 3.0$ & $5.2 \pm 0.5$ & $236 \pm 1$ & $267 \pm 1$ & $39.5 \pm 1.1(40)$ \\
\hline $\begin{array}{c}\text { SMP with } \\
\text { Triphen small } \\
\text { molecule additive }\end{array}$ & $38.9 \pm 0.3$ & $12.3 \pm 1.3$ & $247 \pm 3$ & $279 \pm 4$ & $-\quad(22)$ \\
\hline
\end{tabular}

For the small molecule antioxidant SMPs, the Methyl SMP displayed increased $\mathrm{T}_{g}$ from $55.3{ }^{\circ} \mathrm{C}$ (control) to $61.5{ }^{\circ} \mathrm{C}$, which is attributed to the aromatic groups in the SMP backbone. Interestingly, Piper did not display an increase, but this may be due to the antioxidant being a pendant group rather than a crosslinker, with the increase in chain ends counterbalanced by the increase in backbone chain rigidity due to the pendant groups. The physical addition of the BHT $\left(\mathrm{T}_{g}=57.2^{\circ} \mathrm{C}\right)$ did not statistically alter the $\mathrm{T}_{g}$. Thio and Triphen seemed to act as plasticizers causing the drop in the $\mathrm{T}_{g}$ of the SMP, with $41.0{ }^{\circ} \mathrm{C}$ and $38.9{ }^{\circ} \mathrm{C}$, respectively. A melt transformation was found for Thio at approximately $40{ }^{\circ} \mathrm{C}$ (SI Figure 18), which corresponds to the melting point of the monomer. The other SMPs did not display melting points, despite all monomers displaying melting points within the examined range $\left(\mathrm{BHT}_{m} c a 70{ }^{\circ} \mathrm{C}\right.$, Piper $_{m} c a$ $130{ }^{\circ} \mathrm{C}$, Methyl $\mathrm{T}_{m} c a 125^{\circ} \mathrm{C}$, and Triphen $\mathrm{T}_{m} c a 22^{\circ} \mathrm{C}$ ).

The use of the microparticles with antioxidants did not alter the $\mathrm{T}_{g}$. Control microparticles were found to not have a significant $\mathrm{T}_{g}$, an expected result due to the high concentration of urea linkages; microparticle behavior is discussed further by Kong et al. ${ }^{31}$ Dry $\mathrm{T}_{g}$ of the microparticle SMP composites was found to be $c a 65^{\circ} \mathrm{C}$, regardless of additive species. Wet $\mathrm{T}_{g}$ was $c a 28^{\circ} \mathrm{C}$. The microparticles themselves had $\mathrm{T}_{g}$ of $c a 90^{\circ} \mathrm{C}$ and $150{ }^{\circ} \mathrm{C}$, consistent with results reported by Kong for similar materials. ${ }^{31}$ However, unlike Kong's results, no peak at $200{ }^{\circ} \mathrm{C}$ was seen, which was expected for our system. ${ }^{31}$ Additionally, extraction of the particle core and addition of the TEA removed the $\mathrm{T}_{g}$ at $150{ }^{\circ} \mathrm{C}$ and added a $\mathrm{T}_{g}$ at $c a 43{ }^{\circ} \mathrm{C}$ consistent with the thermal behavior for a similar polyurethane system. ${ }^{11}$

Thermal degradation of the control composite SMP composition displayed an onset degradation of $c a 240{ }^{\circ} \mathrm{C}$ (derivative local maxima of $c a 275^{\circ} \mathrm{C}$ ), indicative of polyurethane thermolysis. Methyl and BHT antioxidants resulted in increased derivative peaks of thermal degradation temperatures (control at $\mathrm{ca} 273^{\circ} \mathrm{C}$, BHT at $303^{\circ} \mathrm{C}$, and Methyl at $299^{\circ} \mathrm{C}$ ). All antioxidant SMPs, except for the Thio, displayed an increased onset of thermal degradation, a trend which was repeated with the antioxidant-containing microparticles. This trend was reproduced for 
bare particles. Literature values for polyurethane thermal degradation display similar thermal degradation values in the range of $230-250{ }^{\circ} \mathrm{C}$ for aliphatic polymers; full thermal degradation curves are displayed in SI Figure 18. ${ }^{11,40-41}$

\section{Shape Memory Characterization}

All composite SMPs examined have similar shape recovery profiles compared to the control SMP, unlike the SMPs containing small molecule antioxidants. This desired outcome was achieved for the first time, by incorporating functional polymer microparticles; previous attempts have failed to deliver with regards to shape memory, with metal or metal oxide-based particles, including tungsten, zirconium oxide, barium sulfate, and iron oxide, altering the recoverable strains and strain recovery rates. ${ }^{14-16,35,42}$ With small molecule antioxidants, Methyl SMPs displayed little shape recovery ( $c$ a 35\% recoverable strain) (Figure 5) and Piper had slightly reduced shape memory ( $\mathrm{ca}$ 90\% recoverable strain). The Methyl-loaded particles and the Piperloaded particles have superior shape recovery behavior compared with the small molecules. Piperloaded composite SMPs, the slowest recovering composition, are capable of $100 \%$ strain recovery over 15 minutes (with full recovery occurring at $c a 10$ minutes) with similar recovery kinetics to the control material. By comparison, Piper, added as a small molecule, results in only ca $80 \%$ recovered strain by 10 minutes and a final recoverable strain of $c a 90 \%$. The other SMP species did not have significantly altered shape memory properties. For the Methyl SMPs, the more rigid aromatic backbone having formed urethane linkages and thereby increasing backbone rigidity is the most plausible cause for reduced strain recovery. For Piper SMPs, the decrease in crosslink density due to increased chain ends (as a result of adding the antioxidant) will reduce the recoverable strain. ${ }^{8}$

As demonstrated through the fluorometry examination of $\mathrm{PhB}$-containing particles (Figure 3 ), there are some reactions between isocyanates and surface groups of the microparticles, which in the case of $\mathrm{PhB}$, result in urethane formation; in the case of metal and metal oxide additives, which were not characterized for surface chemistry, the incorporation of the particles into the polymer matrix during foam blowing may change the crosslinking density locally, but microscopic analysis did reveal pore instability and collapsed sections of the SMP foam when using such additives. ${ }^{14}$ These sections of increased density may dramatically have altered the shape recovery kinetics simply due to fracture of the more dense sections. ${ }^{15,35}$ Regardless, with the presented polyurethane microparticles, superior incorporation without pore collapse and additional crosslinking at the particle surface is achieved and does not impact the strain recovery.

\section{Payload Delivery and Stimuli Response}

Small molecule containing SMPs were found to release nearly all of the antioxidants in the matrix during cleaning, as determined by GCMS, and were therefore not examined for release studies. Nile blue chloride and $\mathrm{PhB}$, in addition to BHT, Methyl, and Piper composite SMPs were examined for release of their respective molecule in vitro (Figure 6). The initial release of additives from the composite SMP was measured using GCMS (SI Table 2, SI Figure 19) and $\mathrm{UV}$-vis. At $1 \mathrm{hr}$, which would be the equivalent of cleaning the SMP prior to device packaging and sterilization, the BHT particles appeared to have released the majority of the releasable payload. BHT-synth released more than $80 \%$ of the available antioxidant and BHT-load had released $\mathrm{ca} 50 \%$. These $1 \mathrm{hr}$ results are similar to those reported by Yoo et al. using Sudan Blue in a poly(urea urethane) system. ${ }^{43}$ By $1 \mathrm{wk}, 91 \%$ of the available BHT had been released from the 
BHT-synth and $\mathrm{ca} 75 \%$ from BHT-load. In an effort to improve loading and to examine the combination of small molecules and compositing, BHT and BHT (containing both microparticles and small molecule antioxidants) SMPs were examined and were found to release nearly 50\% of the available antioxidant by $1 \mathrm{wk}$. It is important to note that the solution concentration of the BHT and BHT SMPs was approximately twice of BHT-Load or BHT-Synth, demonstrating the potential of these methods for applications other than the biostability tuning of the SMP. By $1 \mathrm{wk}$, the release from the SMPs appeared to have stabilized for simple diffusion driven release, further indicating the possibility of retaining some gravimetric resilience even after diffusion has occurred.

The Piper and Methyl SMPs retained greater than $90 \%$ of the payload by 3 weeks, as did the particles containing $\mathrm{PhB}$ and Nile fluorescent dyes. Particles in solution displayed a similar, if the more rapid trend, compared with the composite SMPs, demonstrating the potential of the SMPs as a matrix material for sustained release. Tuning the hydrophobicity and size of the added molecule would obviously factor into the release profiles, and further work is needed to characterize interaction of the matrix and particle wall in terms of release (such as methods presented by Yoo et al.); for long term sustained release or for oxidation-responsive conditions, the presented system seems to show promise. ${ }^{43-45}$

The incorporation of fluorescent dye also presented an opportunity to incorporate an environmental detection functionality. Nile chloride emits a wide range of wavelengths depending on solvent and $\mathrm{pH}$, and $\mathrm{PhB}$ is visible through blood as a way of monitoring the device's location. ${ }^{14}$ SMP composites with $\mathrm{PhB}$, Nile blue, or both were examined in $1 \mathrm{M}$ solutions with $\mathrm{KOH}, \mathrm{HNO}_{3}$, $\mathrm{RO} \mathrm{H}_{2} \mathrm{O}$, and $\mathrm{H}_{2} \mathrm{O}_{2}$. Responsiveness for Nile particles and foam was found with the acidic solution, with a strong emission peak displayed at $538 \mathrm{~nm}$ that is not present in basic or neutral solution, or in the presence of the peroxide. For the Nile composite SMP in a colorimetric assay, a shift in color was first noticed at a $\mathrm{pH}$ of 4 with a subtle color shift, with a more distinct change having occurred at $\mathrm{pH} 3$. Fluorescence emission sweeps were used to determine the shift in emission peaks, from a sharper peak $576 \mathrm{~nm}$ and a broader peak at $471 \mathrm{~nm}$ for basic $\mathrm{pH}(\mathrm{pH}=12)$, to two more narrow peaks centered at $626 \mathrm{~nm}$ and $548 \mathrm{~nm}$. With an optical tissue window in this region, it is hypothesized that it would be possible to remotely monitor the environmental conditions at the SMP-tissue interface through fluorescence microscopy. ${ }^{14}$ 

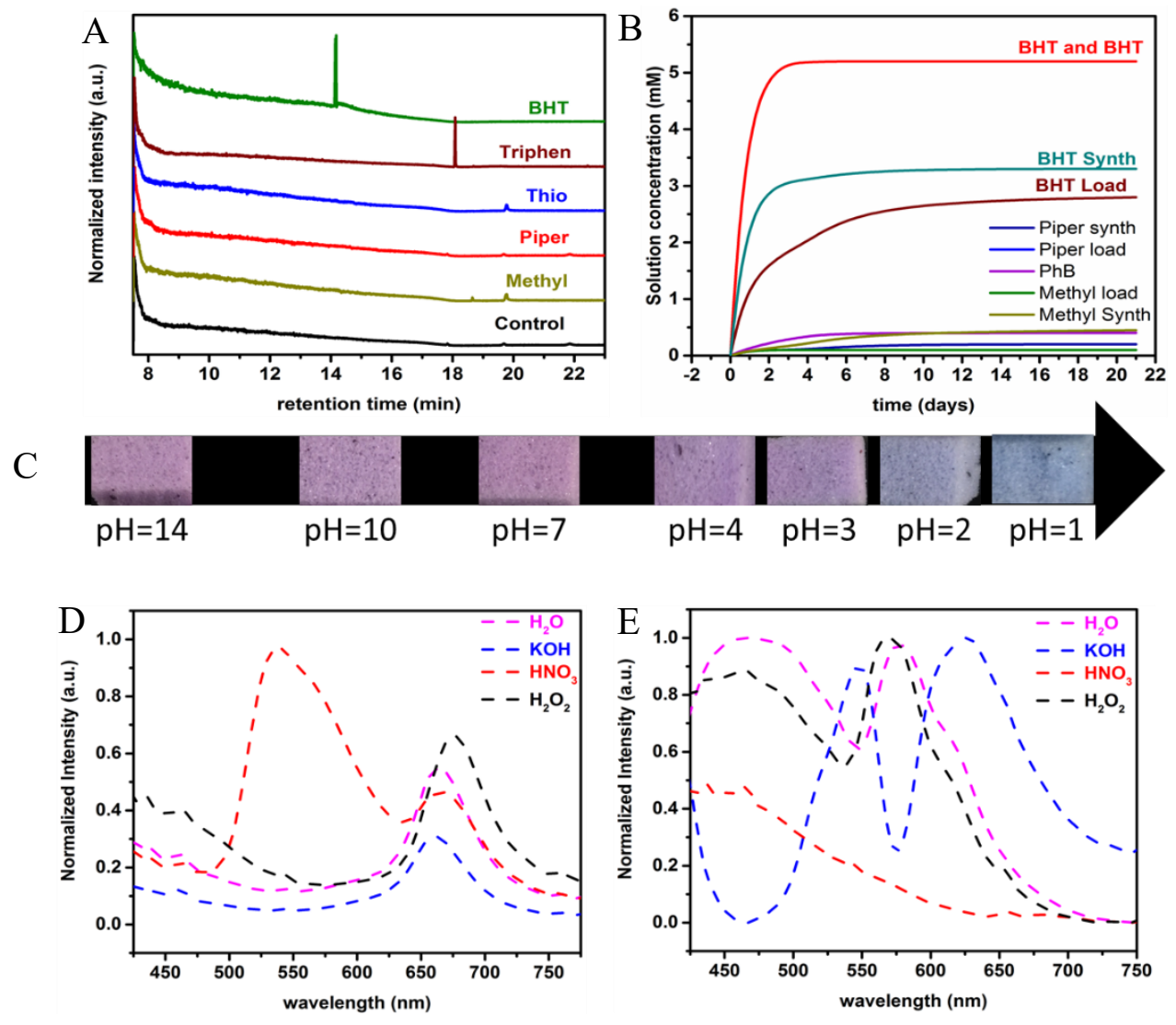

Figure 6. GCMS profiles displaying extraction of small molecule antioxidants (A) and release of payloads from microparticle composites at $37^{\circ} \mathrm{C}$ in $\mathrm{H}_{2} \mathrm{O}(\mathrm{B})$, confirming that while the BHT antioxidants were primarily removed using solvent washes, sufficient retention of active molecules is achieved through the use of microparticle composite SMPs. Responsiveness of composite SMPs loaded with Nile blue (D), and PhB with Nile blue (E) (C) as determined through fluorescence emissions in $1 \mathrm{M}$ solutions. The colorimetric response of SMPs is displayed with a visual change according to $\mathrm{pH}$ for dual loaded composite SMP (C).

\section{Gravimetric Analysis}

Gravimetric analysis was performed with the intent of determining SMP rate of degradation using conditions determined for the control materials in a porcine vascular aneurysm, with experimental testing using accelerated conditions used to determine real time equivalency. ${ }^{11}$ The selected antioxidants had a varied performance with regards to enhancing SMP biostability when incorporated as small molecules into the polymer matrix. When directly incorporated into the SMP as small molecules, the BHT was not retained in the SMP matrix, as confirmed through release studies, and the Methyl formed urethane linkages that could no longer act as radical scavengers. Triphen was also found to be removed during cleaning; Thio did not seem to be removed through diffusion but also did not improve oxidative biostability. BHT, Methyl, Triphen, and Thio SMPs all displayed degradation rates that match the control of SMPs. Piper was the only small molecule antioxidant that retained mass during the testing, with no gravimetric change recorded over the initial three days. After this initiation period, the degradation seemed to follow 
the behavior of the control materials, indicating that the Piper is preferentially oxidized and once consumed, oxidation begins on the amino-alcohol units of the SMP. Interestingly, when the diisocyanate species was altered to the methylated TMHDI, BHT directly incorporated during synthesis resulted in statistically increased mass retention, on the same order as Piper in the HDI series; Piper was not as effective in the TMHDI SMPs (SI Figure 20) compared to BHT.

However, while microparticles enhance the utility of same antioxidants, for the Piper series it was found to be no more effective than the addition of small molecules into the bulk. This is attributed to the maximum loading efficiency of 50\% particle mass, as well as the cleaning that is necessary for SMPs prior to any medical application. 10\% loading of particles in SMP composites would provide $c a 0.85 \mathrm{~g}$ of antioxidant. Gravimetric testing revealed, as hypothesized, that the majority of the small molecule antioxidants diffused out of the matrix during cleaning, leaving on the matrix materials behind, which underwent oxidatively-induced mass loss at the same rate as the control SMPs. Piper antioxidants delayed the onset of mass loss, as more of the active antioxidant was retained compared to the other formulations. After this initiation period ( 3 days in $20 \% \mathrm{H}_{2} \mathrm{O}_{2}$ with $0.1 \mathrm{M} \mathrm{CoCl}_{2}$ ), the rate of mass loss was found to approximately match that of the other formulations for the initial $50 \%$ mass. At this point, the rate of mass loss was reduced to $c a$ $60 \%$ and extended the material life from 15 days to 25 days. The use of microparticles did allow for better retention of BHT and Methyl antioxidant species, thereby enhancing SMP biostability to approximately the same degree as the Piper SMPs.

Gravimetric results were supported by SEM imaging (Figure 8), where foam membranes were found to be relatively intact post-synthesis and after cleaning. Studies of solvent diffusion into porous polyurethanes have indicated that the outer pores will degrade primarily, as will the pore membranes, based upon the Fickian-derived diffusion model of moisture into polyurethane foams. ${ }^{46}$ Poly(ether urethane) foam membranes, materials which are also oxidation susceptible, will form holes or begin to erode at existing pinholes and open the cell pore, and the foam struts will undergo pitting and surface erosion followed by the eventual collapse of the bulk matrix. ${ }^{47-48}$ This reported behavior is similar to the presented SMPs, where the membranes erode away rapidly over the course of hours for the control SMPs, with complete membrane etching by 72 hrs and material collapse by 7 days; this behavior is also representative of in vivo oxidation of similar materials. ${ }^{11}$ While these SMPs were not specifically imaged for surface blistering and strut cracking, these factors may also contribute to the material collapse; a lack of such features may be due to the rapid oxidatively induced surface erosion of the material. ${ }^{49}$

By contrast, the antioxidant SMPs displayed increased resistant to physical changes. Membranes were found to remain intact over the initial 72 hours, followed by the same etching process as the control. In the first 72 hours, polymer etching is still occurring but is counterbalanced by the diffusion of antioxidants from the SMP matrix, as well as the release of antioxidants from the etching process. The antioxidants will scavenge the peroxy radicals at the SMP-solution interface and reduce oxidation of the amino-alcohols, and ultimately this reduces the polymer chain scission initially. After consumption of the antioxidants, SMP degradation occurs in the same manner as the controls and will eventually result in the collapse of the foam structure. Qualitatively, membrane porosity increased moderately, while the strut diameter decrease was faster than that for the control compared to the antioxidant SMPs, with composite SMPs displaying the greatest oxidation resistance overall compared to the antioxidant small molecules. This may factor into control of the gravimetric changes, as the gradual erosion of pores 
and struts places microparticles in direct contact with the solution, allowing for more rapid antioxidant diffusion.

\section{Real Time Oxidative Biostability Calculations}

Based upon previously obtained in vivo data, the rate of oxidatively-induced mass loss for the control composition is known, as are the degradation products of the SMPs. ${ }^{11}$ The amino alcohols are known to oxidize to N-oxides, followed by lower amines and corresponding aldehydes, which may further oxidize to carboxylic acids or are part of the tissue integration process, depending on location and foreign body response. ${ }^{11}$ The use of TEA is designed to increase long-term cytocompatibility of the particles and particle degradation products, as TEA will not form oxalic acid as a potential by-product, unlike HPED. ${ }^{11}$ In this same study, the real time rate of degradation in a porcine aneurysm was determined to be most accurately modeled by $2 \% \mathrm{H}_{2} \mathrm{O}_{2}$, with the lifespan of the control materials found to be $c a 800$ days. ${ }^{11}$ The rate of control SMP mass loss was scaled using the accelerated experimental tests presented in the previous section, and approximations of real time oxidative mass loss were calculated. ${ }^{11}$ For Methyl SMP composites, the lifespan of the material is $c a 1120$ days. Piper and BHT had predicted lifespans of ca 1200 days or greater.

From a toxicological risk perspective of the degradation products, increasing the time to total mass loss (decreasing the rate of degradation) achieves a lower production rate of degradation products and a reduced risk, as the overall exposure rate per day is reduced by extending the material lifespan by more than $30 \% .{ }^{11}$ For the SMP matrix, toxicity assessments were briefly undertaken using a literature review of the degradation products, and it appears the oxalic acid is the most concerning degradation product. ${ }^{50-51}$ In selecting TEA as the alcohol monomer, complete particle degradation does not risk the generation of oxalic acid or glyoxal and overall toxicity risk from the SMP is reduced. For oxalic acid, $0.54 \mathrm{mg} / \mathrm{kg}$ body weight/day $(37.8 \mathrm{mg} /$ day for an average $70 \mathrm{~kg}$ human) is the accepted maximum threshold for no adverse effects. ${ }^{50-51} \mathrm{In}$ the presented control SMPs, this corresponds to $c a 37 \mathrm{mg}$ total; the use of Piper or BHT to increase oxidative stability would, therefore, produce SMPs that generate an average of ca $31 \mu \mathrm{g}$ oxalic acid per day, three orders of magnitude below the threshold for concern. From the cytocompatibility analysis, it appears that oxalic acid is the most concerning degradation product. In selecting TEA as the alcohol monomer of the particles, complete particle degradation is not limited by the generation of oxalic acid or glyoxal. 

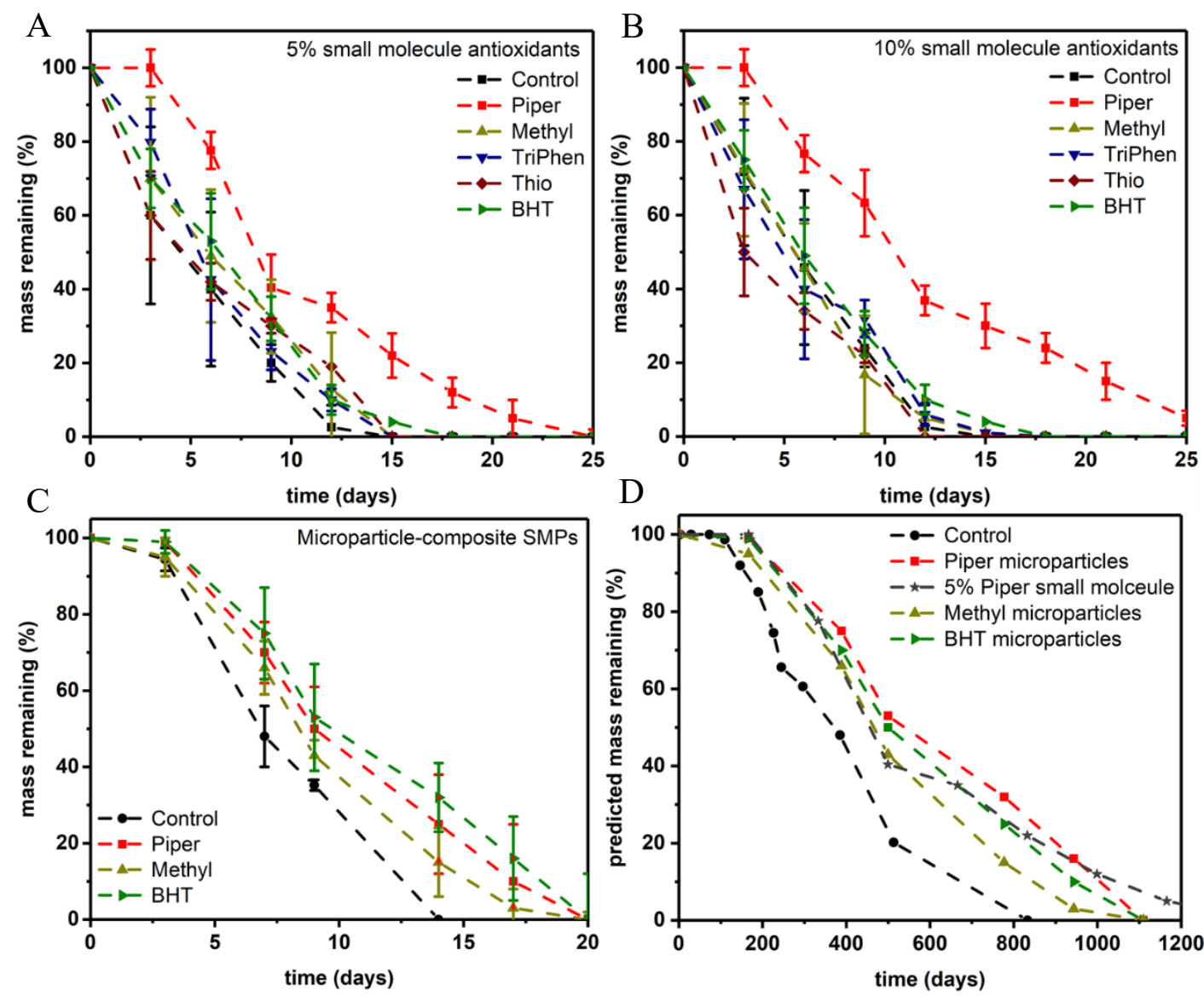

Figure 7. Gravimetric analysis of small molecule containing SMPs (5\% wt, A; $10 \% \mathrm{wt}, \mathrm{B})$ and composite SMPs (5\% weight, C) in $\left(20 \% \mathrm{H}_{2} \mathrm{O}_{2}\right.$ with $0.1 \mathrm{M} \mathrm{CoCl}_{2}$ at $\left.37^{\circ} \mathrm{C}\right)$. Theoretical calculations of gravimetric behavior were performed to compare the real time control lifespan with small molecule and microparticle composite SMPs for a $2 \% \mathrm{H}_{2} \mathrm{O}_{2}$ solution (porcine aneurysm conditions) at $37^{\circ} \mathrm{C}(\mathrm{n}=7)$. 

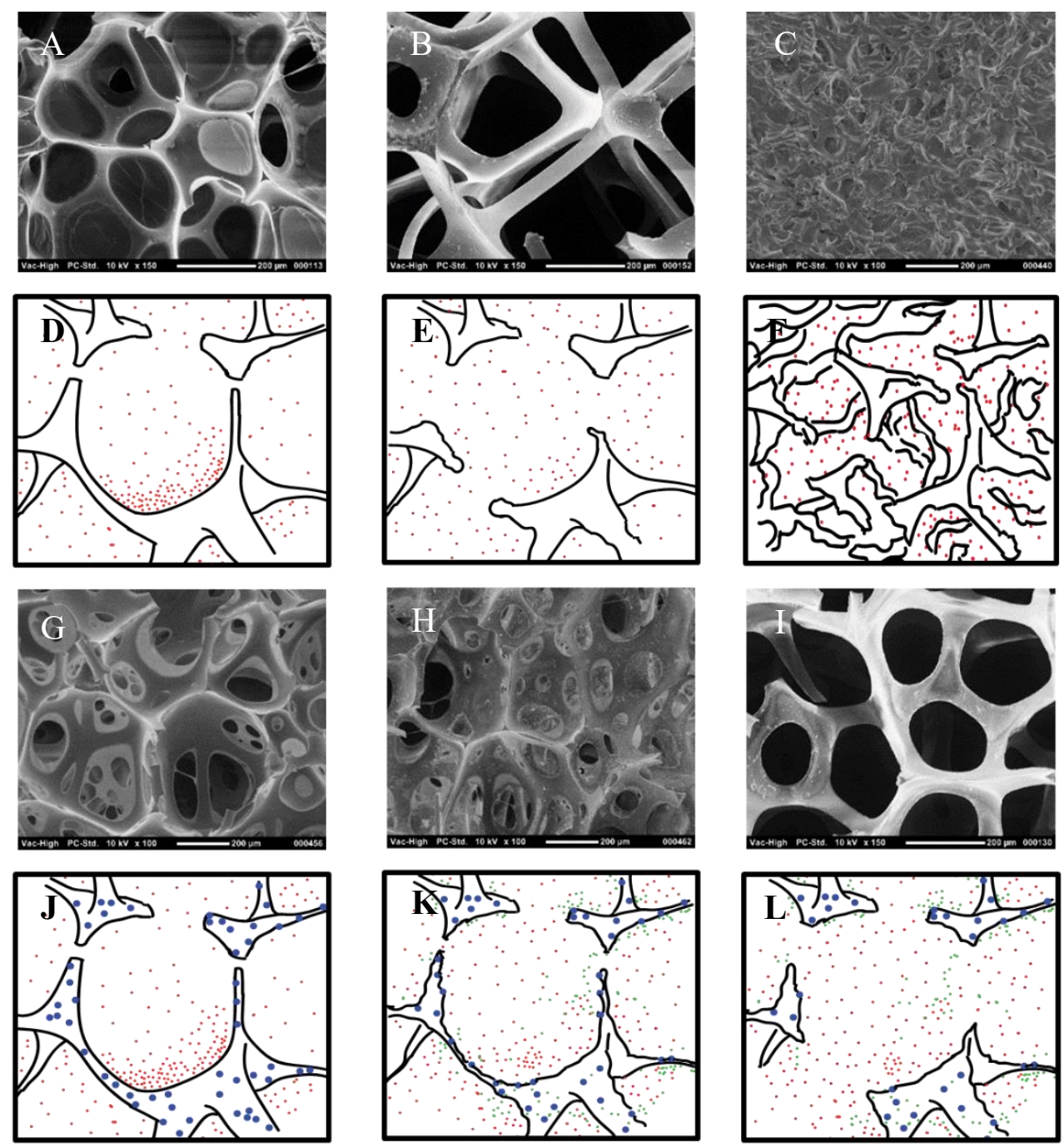

Original Pore

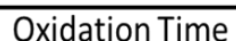

Collapsed Pore(s)

Figure 8. SEM images of the degradation of composite SMPs compared to control and selected small molecule antioxidant-containing SMPs over the course of 7 days in accelerated conditions $\left(20 \% \mathrm{H}_{2} \mathrm{O}_{2}\right.$ with $0.1 \mathrm{M} \mathrm{CoCl}_{2}$ at $37^{\circ} \mathrm{C}$ ) with red dots denoting peroxide, green dots denoting antioxidants and blue dots displaying microparticles: (A) day 0, (B) day 3, (C) day 7, with the corresponding schematic displaying the erosion of membranes and reduction of strut mass, followed by SMP collapse over the same time period (D-F). 5\% wt microparticles-containing Piper SMP degradation behavior of the SMP composites (D, the equivalent of $2 \% \mathrm{H}_{2} \mathrm{O}_{2}$ at $37^{\circ} \mathrm{C}$ ). Control SMP and Piper SMP at day $0(\mathrm{G})$, day $3(\mathrm{H})$, and day 7 (I) is presented with the corresponding schematic of the same time displaying release of antioxidants accompanying the erosion and revealing the microparticles within the SMP matrix. This ultimately allows the foam to retain mass and the pore membranes over the initial 3 days in accelerated oxidative solutions. 


\section{Conclusions}

The use of phenolic and HALS antioxidants was demonstrated for improving oxidative stability of SMPs, with only the HALS antioxidant retaining functionality when directly incorporated into the SMP. However, phenolic antioxidants could be retained in the SMP matrix when incorporated in microparticles. The strain to failure and the elastic moduli were impacted by the inclusion of antioxidants directly in the SMP. However, the composite SMPs displayed no statistical variation in either property, independent of antioxidant species examined. The retention of the antioxidants was examined using in vitro release studies, which ultimately was used to determine that small molecule antioxidants are not well retained in the SMP matrix for the examined formulations, but through the use of microparticles, retention could be greatly enhanced. This retention was demonstrated to be sufficient for increasing the lifespan of the SMP by $25 \%$ to $50 \%$, according to calculated values, depending on the antioxidant and incorporation method. For the clinical use as a biomaterial, the incorporation of antioxidant-containing microparticles to reduce degradation was demonstrated to lower the exposure level per day of a degradation product to three orders of magnitude below the established limit of concern for oxalic acid, demonstrating the value of this method.

\section{AUTHOR INFORMATION}

\section{Corresponding Author}

*Andrew C Weems, Department of Biomedical Engineering, Texas A\&M University, College

Station, TX.77843, andrewc.weems@email.tamu.edu

\section{Present Addresses}

$†$ Andrew C Weems, Department of Chemistry, University of Birmingham, Birmingham, United Kingdom, B15 2TT, a.c.weems@bham.ac.uk.

\section{Author Contributions}

ACW worked on the experimental design, performed all bulk and model compound studies, analyzed and processed the data, and wrote the manuscript. WL worked on experimental design and characterization of microparticles, as well as data analysis and manuscript critical review. 
LMC and DJM worked on the experimental design, oversaw the experimental work and analysis, and provided a critical review of the manuscript.

\section{Funding Sources}

We would like to acknowledge the NASA Harriett G. Jenkins Fellowship (NNX15AU29H, ACW) and the National Institutes of Health, National Institute of Neurological Diseases and Stroke Cooperative Program in Translational Research (U01NS089692, DJM).

\section{Acknowledgements}

The authors would like to thank Dr. William Wustenburg for scientific discussions on toxicology calculations and biomaterial safety.

\section{References}

1. DK Dempsey, C Carranza, CP Chawla, P Gray, JH Eoh, S Cereceres, EM CosgriffHernandez. Comparative analysis of in vitro oxidative degradation of poly(carbonate urethanes) for biostability screening. J Biomed Mater Res A, 2014, 102A; 3649-3665. DOI:10.1002/jbm.a.35037

2. JR Martin, MK Gupta, JM Page, F Yu, JR Davidson, SA Guelcher, CL Duvall. A porous tissue engineering scaffold selectively degraded by cell-generated reactive oxygen species. Biomaterials, 2014, 35(12), 3766-3776. DOI:10.1016/j.biomaterials.2014.01.026

3. LX Liu, L Zhou, F Pan, Y Gao, X Yuan, D Fan. Comparison of the postoperative incidence rate of capsular contracture among different breast implants: a cumulative meta-analysis. PLOS One, 2015. DOI:10.1371/journal.pone.0116071

4. N Castel, Polyurethane-coated breast implants revisited: a 30 year follow up, Arch Plast Surg, 2015, 42(2), 186-193. DOI: 10.5999/aps2015.42.2.186.

5. C Batich, J Williams, R King. Toxic hydrolysis product from a biodegradable foam implant. J Biomed Mater Res A, 1989, 23 (S14), 311-319. DOI: 10.1002/jbm.820231406.

6. W Sokolowski, A Metcalfe, S Hayashi, L Yahia, J Raymond. Medical applications of shape memory polymers. Biomed Mater, 2007, 2 (1), 23-27. DOI: 10.1088/17486041/2/1/S04.

7. A Metcalfe, AC Desfaits, I Salazkin, L Yahia, WM Sokolowski, J Raymond. Cold hibernated elastic memory foams for endovascular interventions. Biomater, 2003, 24 (3), 491-497. DOI: 10.1016/S0142-9612(02)00362-9. 
8. TS Wilson, JP Bearinger, JL Herberg, JE Marion III, WJ Wright, CL Evans, DJ Maitland. Shape memory polymers based on uniform aliphatic urethane networks. J Appl Polym Sci, 2007, 106(1), 540-551. DOI:10.1002/app.26593.

9. AJ Boyle, TL Landsman, MA Wierzbicki, LD Nash, W Hwang, MW Miller, E Tuzun, SM Hasan, DJ Maitland. In vitro and in vivo evaluation of a shape memory polymer foam-over-wire embolization device delivered in saccular aneurysm models. $J$ Biomed Mater Res B Appl Biomater, 2016, 104 (7), 1407-1415. DOI: 10.1002/jbm.b.33489.

10. J Horn, H Hwang, SL Jessen, BK Keller, MW Miller, E Tuzun, J Hartman, FJ Clubb, DJ Maitland. Comparison of shape memory polymer foam versus bare metal coil treatments in an in vivo porcine sidewall aneurysm model. J Biomed Mater Res B Appl Biomater, 2016, DOI: 10.1002/jbm.b.33725.

11. AC Weems, KT Wacker, JK Carrow, AJ Boyle, DJ Maitland. Shape Memory Polyurethanes with Oxidation-induced Degradation: In vivo and In vitro Correlations for Endovascular Material Applications. Acta Biomater, 2017, 59, 33-44

12. Use of International Standard ISO 10993-1, "Biological evaluation of medical devices-Part 1: Evaluation and testing within a risk management process" guidance for Industry and Food and Drug Administration Staff. US Department of Health and Human Services, Food and Drug Administration, Center for Devices and Radiological Health. June 2016.

13. EM Christenson, JM Anderson, A Hiltner. Antioxidant inhibition of poly(carbonate urethane) in vivo biodegradation. J Biomed Mater Res A, 2006, 76A, 480-490. DOI:10.1002/jbm.a.30506.

14. AC Weems, JE Raymond, AD Easley, MA Wierzbicki, T Gustafson, MBB Monroe, DJ Maitland. Shape memory polymers with visible and near-infrared imaging modalities: synthesis, characterization and in vitro analysis. $R S C A d v, \mathbf{2 0 1 7}, 7,19742-19753$

15. AC Weems, JM Szafron, AD Easley, S Herting, J Smolen, DJ Maitland. Shape memory polymers with enhanced visibility for magnetic resonance- and X-ray imaging modalities. Acta Biomater, 2017, 54, 45-57.

16. SM Hasan, RS Thompson, H Emery, AL Nathan, AC Weems, F Zhou, MBB Monroe, DJ Maitland. Modification of shape memory polymer foams using tungsten, aluminum oxide, and silicon dioxide nanoparticles. RSC Adv, 2016, 6, 918-927. DOI: 10.1039/C5RA22633C.

17. SM Geary, Q hu, VB Joshi, NB Bowden, AK Salem. J Control Release, 2015, 220B, 682-690. DOI: 10.1016/j.conrel.2015.09.002

18. E Makila, MPA Ferreira, H Kivela, S Niemi, A Correia, M Shahbazi, J Hirvonen, HA Santos, J Salonen. Confinement effects on drugs in thermally hydrocarbonized porous silicon. Langmuir, 2014, 30, 2196-2205. DOI: 10.1021/la40257m.

19. EC Wu, J Park, J Park, E Segal, F Cunic, MJ Sailor. Oxidation-triggered release of fluorescent molecules or drugs from mesoporous Si microparticles. ACS Nano, 2008, 2 (11), 2401-2409.DOI: 10.1021/nn800592q.

20. M Kang, J Kim, G Im. Thermoresponsive nanospheres with independent dual drug release profiles for the treatment of osteoarthritis. Acta Biomater, 2016, 39, 65-78. DOI: 10.1016/j.actbio.2016.05.005.

21. F Tewes, OL Gobbo, C Ehrhardt, AM Healy. Amorphous calcium carbonate basedmicroparticles for peptide pulmonary delivery, ACS Appl Mater Inter, 2016, 8, 11641175. DOI: 10.1021/acsami.5b09023. 
22. D Jeong, C Kang, E Jung, D Yoo, D Wu, D Lee. Porous antioxidant polymer microparticles as therapeutic systems for the airway inflammatory diseases. $J$ Control Release, 2016, 233, 72-80. DOI: 10.1016/j.conrol.2016.04.039.

23. S Park, J Yoon, S Bae, M Park, C Kang, Q Ke, D Lee, PM Kang. Therapeutic use of $\mathrm{H}_{2} \mathrm{O}_{2}$-responsive anti-oxidant polymer nanoparticles for doxorubicin-induced cardiomyopathy. Biomaterials, 2014, 35 (22), 5944-5953.

24. D Yoo, K guk, H Kim, G Khang, D Wu, D Lee. Antioxidant polymeric nanoparticles as novel therapeutics for airway inflammatory diseases. Inter J Pharm, 2013, 450 (1-2), 8794. DOI: 10.1016/j.ijpharm.2013.04.028.

25. VF Fiore, MC Logton, S Roser-Page, SC Yang, J Roman, N Murthy, TH Barker. Polyketal microparticles for therapeutic delivery to the lung. Biomater, 2010, 31 (5), 810817. DOI: 10.1016/j.biomaterials.2009.09.100.

26. Y Feng, S Zhang, H Wang, H Zhao, J Lu, J Guo, M Behl, A Lendlein. J Control Release, 2011, 152 (1), 21-23. DOI: 10.1016/j.conrel.2011.08.098.

27. B Li, KV Brown, JC Wenke, SA Guelcher. Sustained release of vancomycin from polyurethane scaffolds inhibits infection of bone wounds in a rat femoral segmental defect model. J Control Release, 2010, 145 (3), 221-230. DOI: 10.1016/j.conrel.2010.04.002.

28. X Kiu, S She, W Tong, C Gao. Preparation of elastic polyurethane microcapsules using $\mathrm{CaCO}_{3}$ microparticles as templates for hydrophobic substances loading. RSC Advanc, 2014, 5, 5775. DOI: 10.1039/c4ra12193g

29. X Li, Y Jiang, F Wang, Z Fan, H Wang, C Tao, Z Wang. Preparation of polyurethane/polyvinyl alcohol hydrogel and its performance enhancement via compositing with silver particles. RSC Adv, 2017, 7, 46480.

30. S Budriene et al, Synthesis and characterization of polyurethane microspheres and their application for immobilization of maltogenase, 2007, DOI: 10.1002/pat.797.

31. XZ Kong, Preparation of core-shell and hollow polyuria microspheres via precipitation polymerization using polyamine as crosslinker monomer, 2013, DOI: 10.1039/C3PY00809F.

32. S Beibmann, M Reisinger, K Grabmayer, G Wallner, D Nitsche, W Buchberger. Analytical evaluation of the performance of stabilization systems for polyolefinic materials. Pt 1: interactions between hindered amine light stabilizers and phenolic antioxidants. Polym Degrad Stabl. 2014, 110, 498-508. DOI: 10.1016/j.polymdegradstab.2014.09.020.

33. H Yamashita, Y Ohkatsu. A new antagonism between hindered amine light stabilizers and acidic compounds including phenolic antioxidant. Polym Degrad Stabl, 2003, 80 (3), 421426. DOI: 10.1016/S0141-3910(02)00373-7.

34. RS Lanigan, TA Yamarik. Final report on the safety assessment of BHT. Intern J Tox, 2002, 21, 19-94. DOI: 10.1080/109158102990096513.

35. AC Weems, JE Raymond, KT Wacker, TP Gustafson, B Keller, KL Wooley, DJ Maitland. Examination of radio-opacity enhancing additives in shape memory polyurethane foams. $J$ Appl Polym Sci, 2015, 132(23). DOI:10.1002/app.42054.

36. WH Guo, WS Wang, XK Yu, XM Peng, NY Ma. Facile route to synthesis and morphology control of anionic waterborne polyurethane hollow microspheres via self-crosslinking reaction. $R S C A d v, \mathbf{2 0 1 5}, 5,80568$. 
37. Q Guo, CJ Bishop, RA Meyer, DR Wilson, L Olasov, DE Schlesinger, PT Mather, JB Spicer, JH Elisseeff, JJ Green. Entanglement-based thermoplastic shape memory polymeric particles with photothermal actuation for biomedical applications. ACS Appl Mater Inter, 2018.

38. B Ketterer, HW Ooi, D Brekel, V Trouillet, Leonie Barner, M Franzreb, C BarnerKowollik. Dual-gated microparticles for switchable antibody release. ACS Appl Mater Inter, 2017, 10, 1450-1462.

39. R Liu, Q Zhang, Q Zhou, P Zhang, H Dai. Nondegradable magnetic poly(carbonate urethane) microspheres with good shape memory as a proposed material for vascular embolization. J Mech Behav Biomed Mater, 2018, 82, 9-17

40. G Wu, J Li, Y Luo. Flame retardancy and thermal degradation mechanism of a novel postchain extension flame retardant waterborne polyurethane. Polym Degrad Stabl, 2016, 123, 36-46.

41. Y Yoo, C Martinez, JP Youngblood. Synthesis and characterization of microencapsulated phase change materials with poly(urea-urethane) shells containing cellulose nanocrystals. ACS Appl Mater Interfaces, 2017, 9 (37), 31763-31776.

42. R Yu, X Yang, Y Zhang, X Zhao, X Wu, T Zhao, Y Zhao, W Huang. Three-dimensional printing of shape memory composites with epoxy-acrylate hybrid photopolymer. ACS Appl Mater Interfaces, 2016, 9, 1820-1829.

43. Y Yoo, C Martinez, JP Youngblood. Sustained dye release using poly(ureaurethane)/cellulose nanocrystal composite microcapsules. Langmuir, 2017, 33, 1521-1532.

44. D Jeong, C Kang, E Jung, D Yoo, D Wu, D Lee. Porous antioxidant polymer microparticles as thereapeutic systesm for the airway inflammatory diseases. J Contr Release. 2016, 233, 72-80.

45. KM Poole, CE Nelson, RV Joshi, JR Martin, MK Gupta, SC Haws, TE Kavanaugh, MC Skala, CL Duvall. ROS-responsive microspheres for on demand antioxidant therapy in a model of diaebetic peripheral arterial disease. Biomater, 2014, 41, 166-175.

46. Z Hou, M Mohamed, JR Nicholas, X Wang, K Chandrashekhara. Experimentation and simulation of moisture diffusion in foam-cored polyurethane sandwich structure. $J$ Sand Struct Mater, 2016, 18 1), 30-49.

47. S Franca de Sa, JL Ferreira, IP Cardoso, R Macedo, AM Ramos. Shedding new light on polyurethane degradation: Assessing foams condition in design objects. Polym Degrad Stabl, 2017, 144, 354-365.

48. A Lattuati-Derieux, S Thao-Heu, B Lavedrine. Assessment of the degradation of polyurethane foams after artificial and natural ageing by using pyrolysis-gas chromatography/mass spectrometry and headspace-solid phase microextraction-gas chromatography/mass spectrometry. J Chromat A, 2011, 1218, 4498-4508.

49. E Pellizzi, A Lattuati-Derieux, B Lavedrine, H Cheradame. Degradation of polyurethane ester foam artifacts: chemical properties, mechanical properties, and comparison between accelerated and natural degradation. Polym Degrad Stabl, 2014, 107, 255-261. 
50. Health Council of the Netherlands: Committeee on Updating of Occupational Exposure Limits. Oxalic acid; Health-based reassessment of administrative occupational exposure limits. The Hague: Health Council of the Netherlands, 2004, 2000/15OSH/106.

51. M Tsujihata. Mechanism of calcium oxalate renal stone formation and renal tubular cell injury. Int J Urolo, 2007, 15 (2), 115-120. DOI: 10.1111/j.1442-2042.2007.01953.x 


\section{Polyurethane microparticles for stimuli response and controlled oxidative degradation in highly porous shape memory polymers}

AC Weems ${ }^{1 *}, \mathrm{~W} \mathrm{Li}^{2}$, DJ Maitland ${ }^{1}$, LM Calle ${ }^{2}$

1. Department of Biomedical Engineering, Texas A\&M University, College Station, TX, 77840

2. Corrosion Technology Laboratory, Kennedy Space Center, NASA, FL, 32899

\section{SUPPLEMENTAL MATERIALS}

Table of Contents:

Antioxidants and Model Reaction $\quad 2$

Microparticle Synthesis and Characterization 3

Composite SMP Synthesis: Spectroscopy $\quad 6$

$\begin{array}{ll}\text { Composite SMP Synthesis: Microscopy } & 10\end{array}$

Composite SMP Synthesis: Thermoechanical Testing 11

Composite SMP Synthesis: Release Studies 12

Composite SMP Synthesis: Gravimetric Studies 13 
<smiles>Cc1cc(Cc2cc(C)cc(C(C)(C)C)c2O)c(O)c(C(C)(C)C)c1</smiles><smiles>[2H]C(C)CCC(C)OC(=O)CCSCCC(=O)OC(C)(C)CCC(C)(C)C</smiles><smiles>c1ccc(OP(Oc2ccccc2)Oc2ccccc2)cc1</smiles>

Species Starting Material (\%) at Urethane formation (\%) Urea formation (\%) conclusion

\begin{tabular}{r|ccc} 
Control (EtOH) & 3.7 & 70.2 & 26.1 \\
Piper & 45.7 & 31.7 & 22.6 \\
Methyl & 32.8 & $28.0(19.5)^{*}$ & 19.5 \\
BHT & 100 & 0 & $\sim 100$ \\
Thio & 100 & 0 & $\sim 100$ \\
Triphen & 100 & 0 & $\sim 100$
\end{tabular}

SI Figure 1. Antioxidant structures used to synthesize oxidatively stable porous SMPs. (A) butylated hydroxytoluene, (B) 2,2,6,6 tetramethyl piperidinol, (C) 2,2'-methylenebis(6-tertbutyl-methylphenol), (D) didodecyl 3,3 thiodipropionate, (E) triphenyl phosphite, and their reactions with hexyl isocyanate in model compound studies with quantified urethane and urea concentrations determined. * denotes where two urethane linkages were formed as determined by LCMS. 

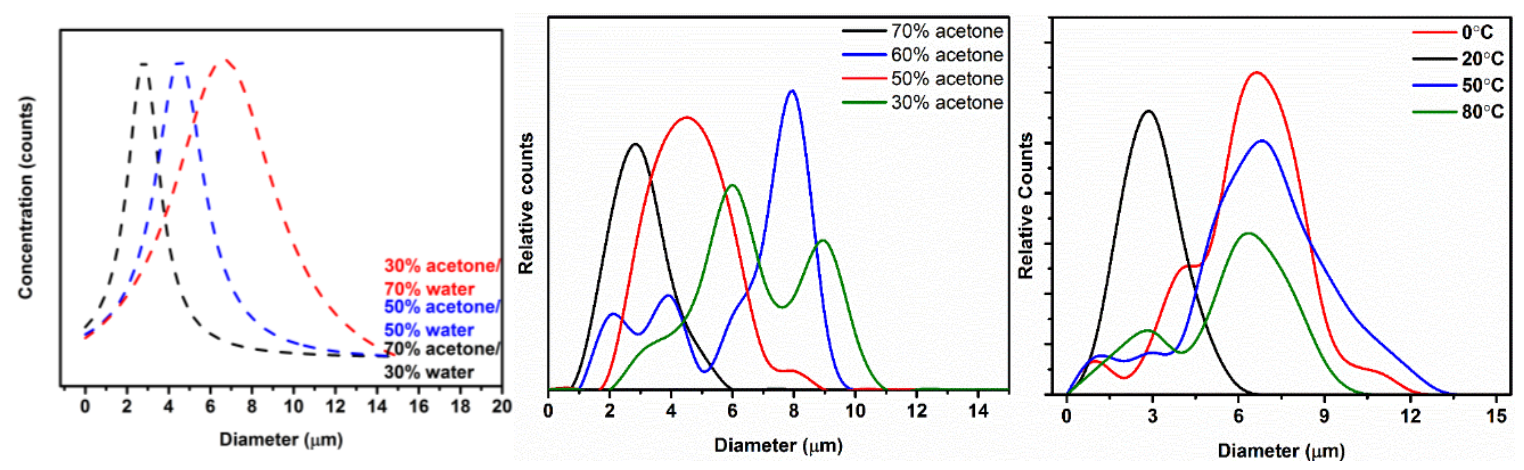

SI Figure 2. Size distribution of IPDI TEA particles synthesized at varied solvent percentages and solution temperatures.

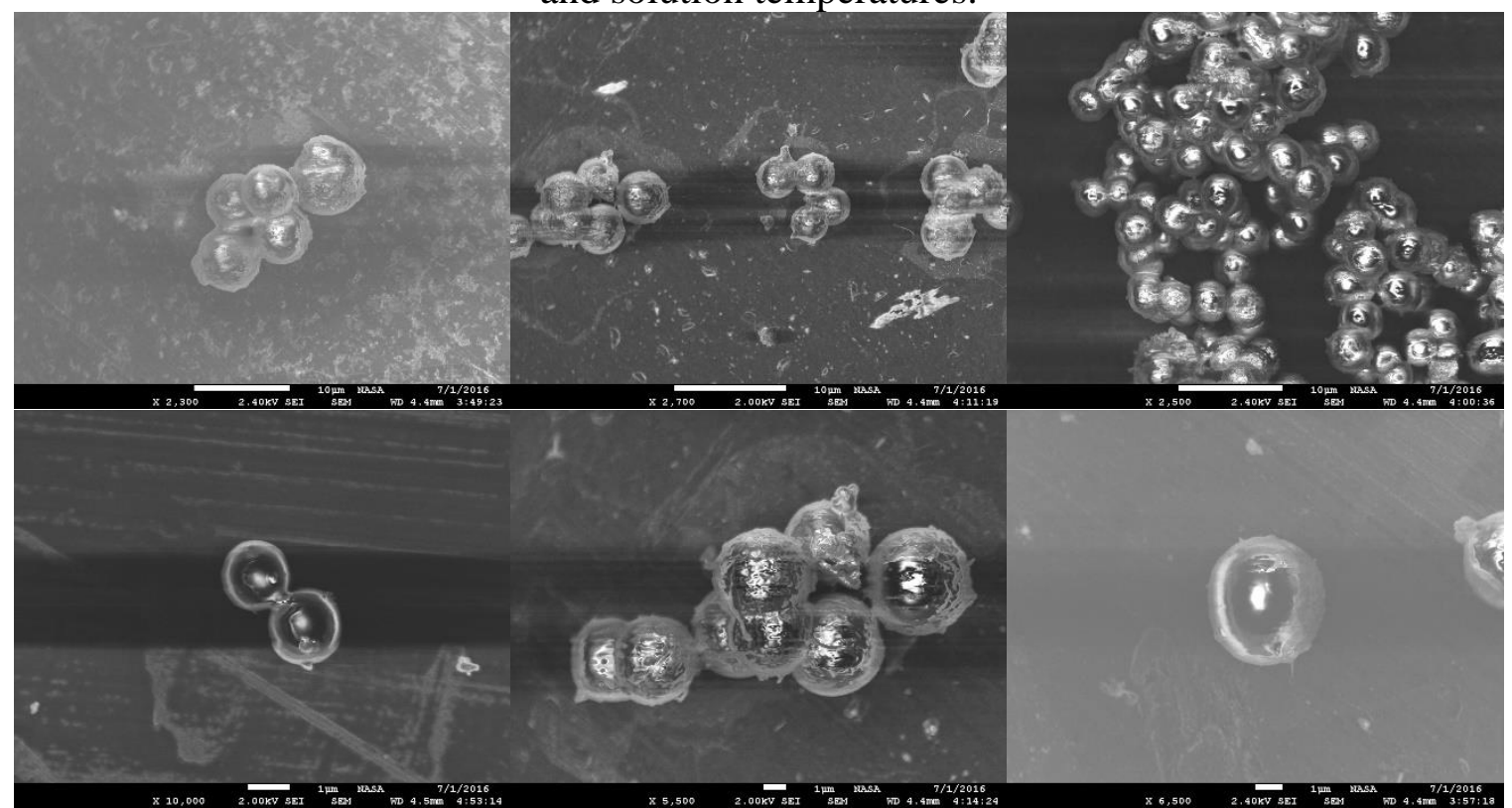

SI Figure 3. SEM images of particles synthesized containing BHT (top) and Piper (bottom).
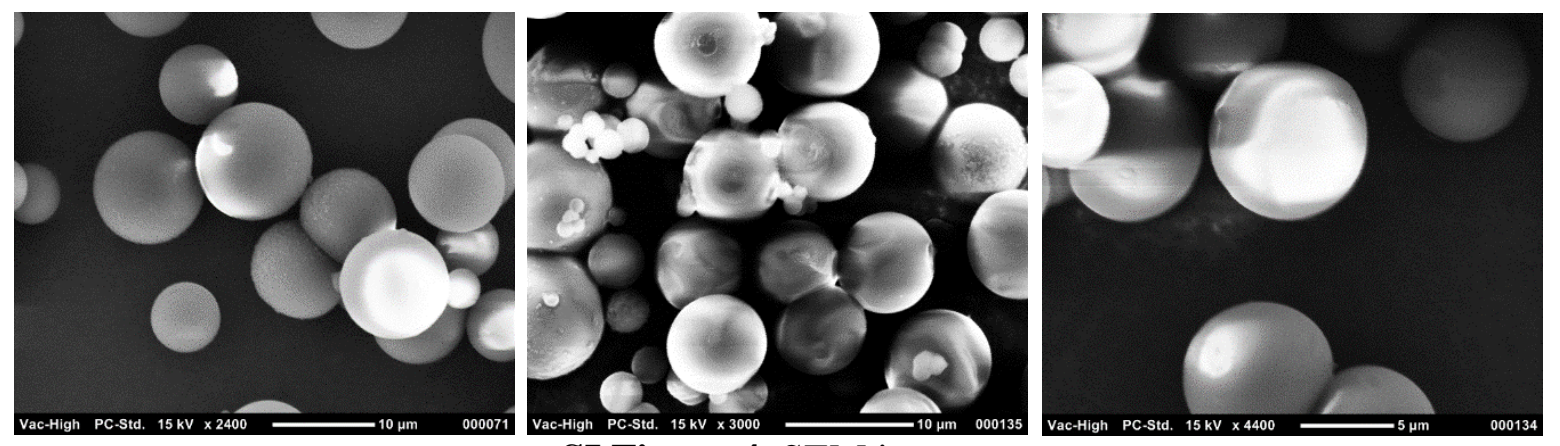

SI Figure 4. SEM images

of microparticles made from TEA (left), HPED (middle) and DEA (right). 


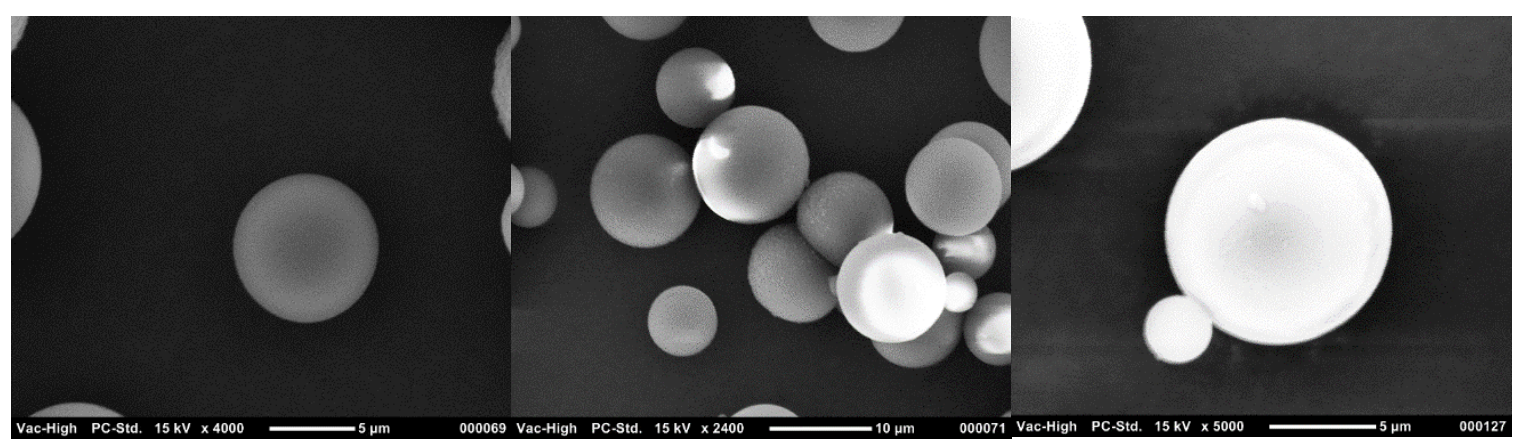

SI Figure 5. SEM images of particles synthesized from IPDI and TEA at $20^{\circ} \mathrm{C}$.

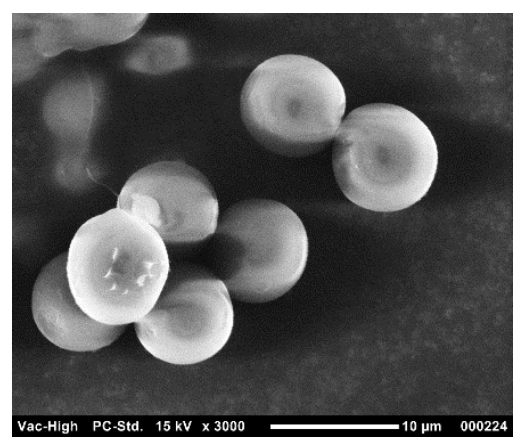

SI Figure 6. SEM images of particles synthesized from IPDI and TEA $0^{\circ} \mathrm{C}$

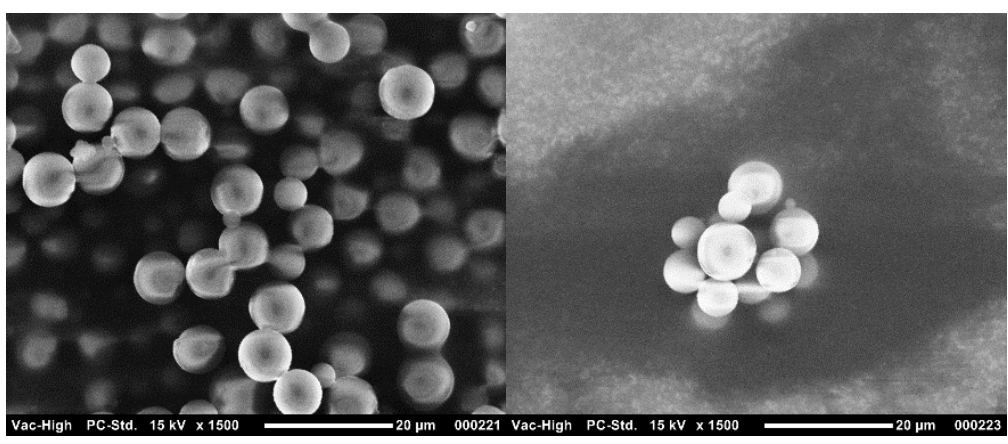

SI Figure 7. SEM images of particles synthesized from IPDI and TEA at $80^{\circ} \mathrm{C}$
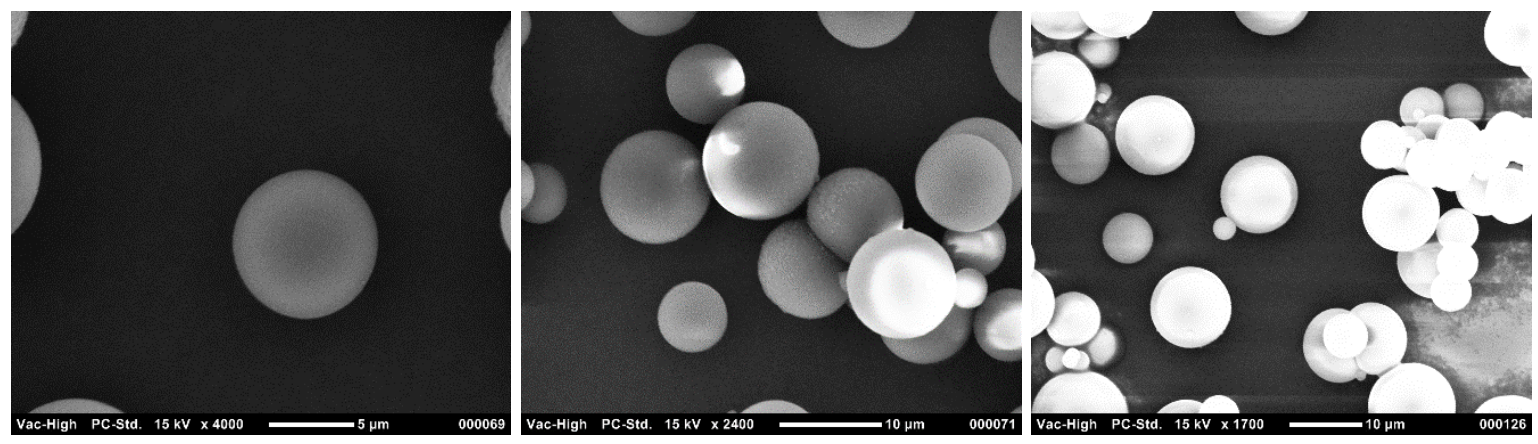

SI Figure 8. SEM images of particles synthesized from IPDI and TEA at $65^{\circ} \mathrm{C}$ 


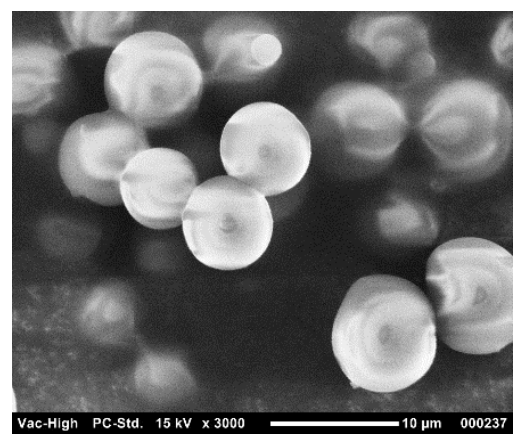

SI Figure 9. SEM image of particles synthesized from IPDI and TEA, 60\% acetone

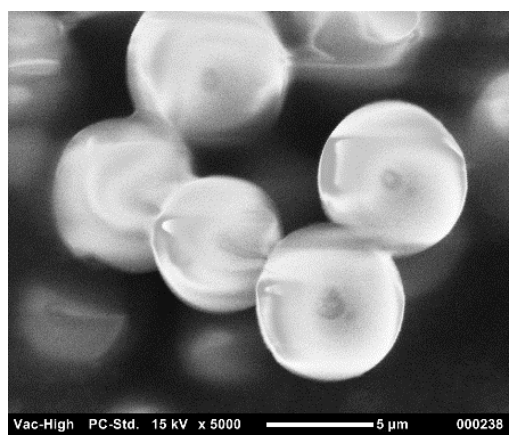

SI Figure 10. SEM image of particles synthesized from IPDI and TEA 50\% acetone

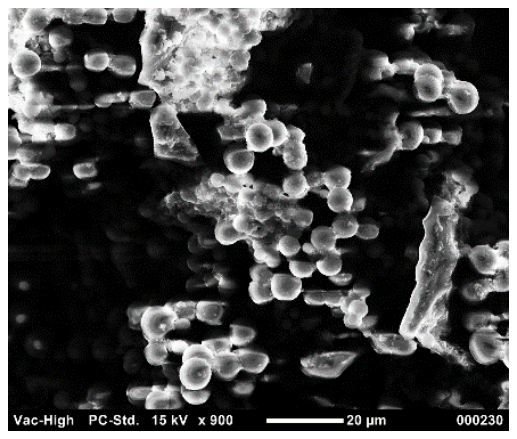

SI Figure 11. SEM image of particles synthesized from IPDI and TEA 30\% acetone 

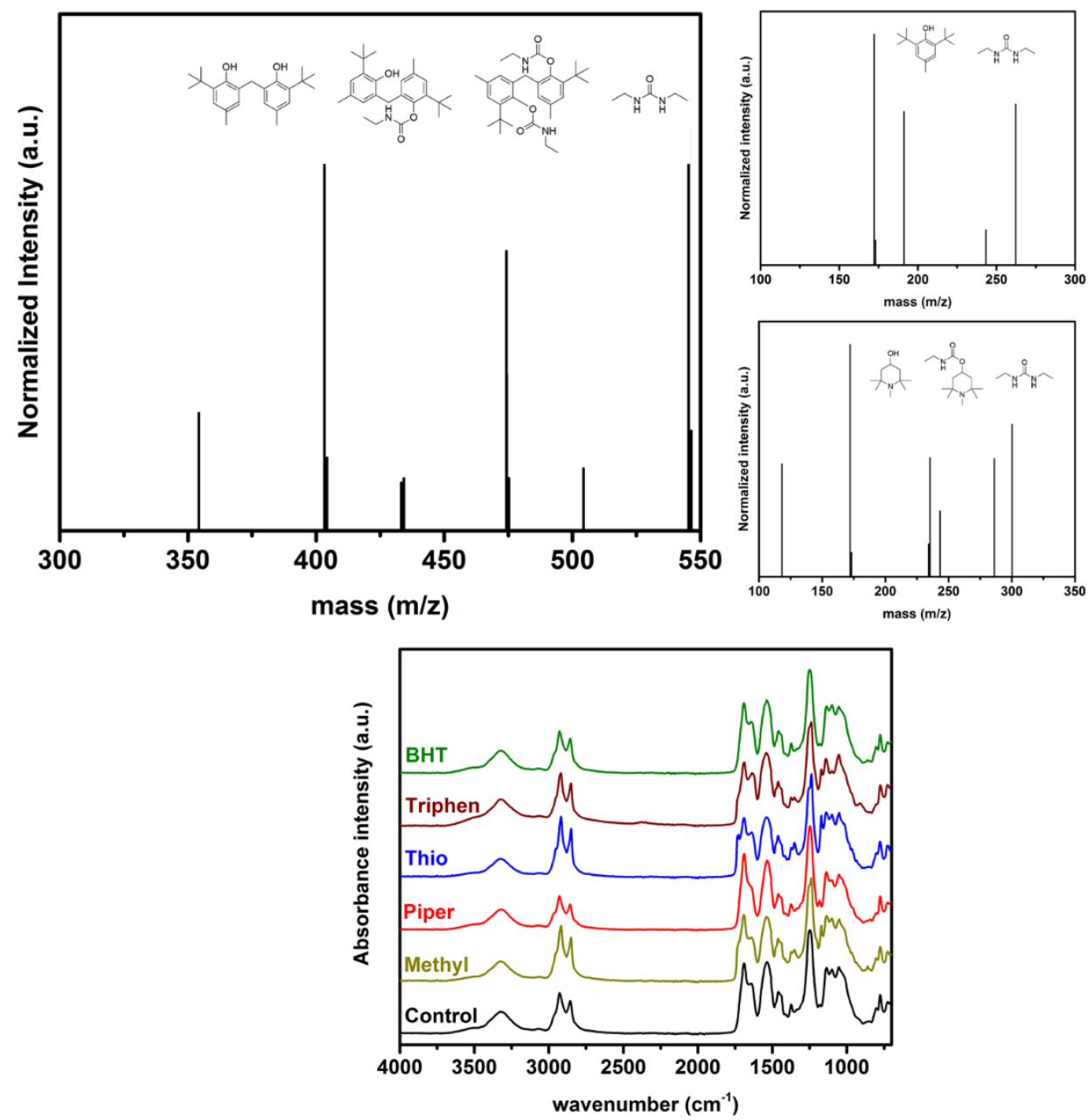

SI Figure 12. Spectroscopic analysis of the antioxidant reactions with isocyanates using model compounds BHT, Methyl and Piper (top), and FTIR-ATR of the antioxidant-containing SMPs (bottom). 

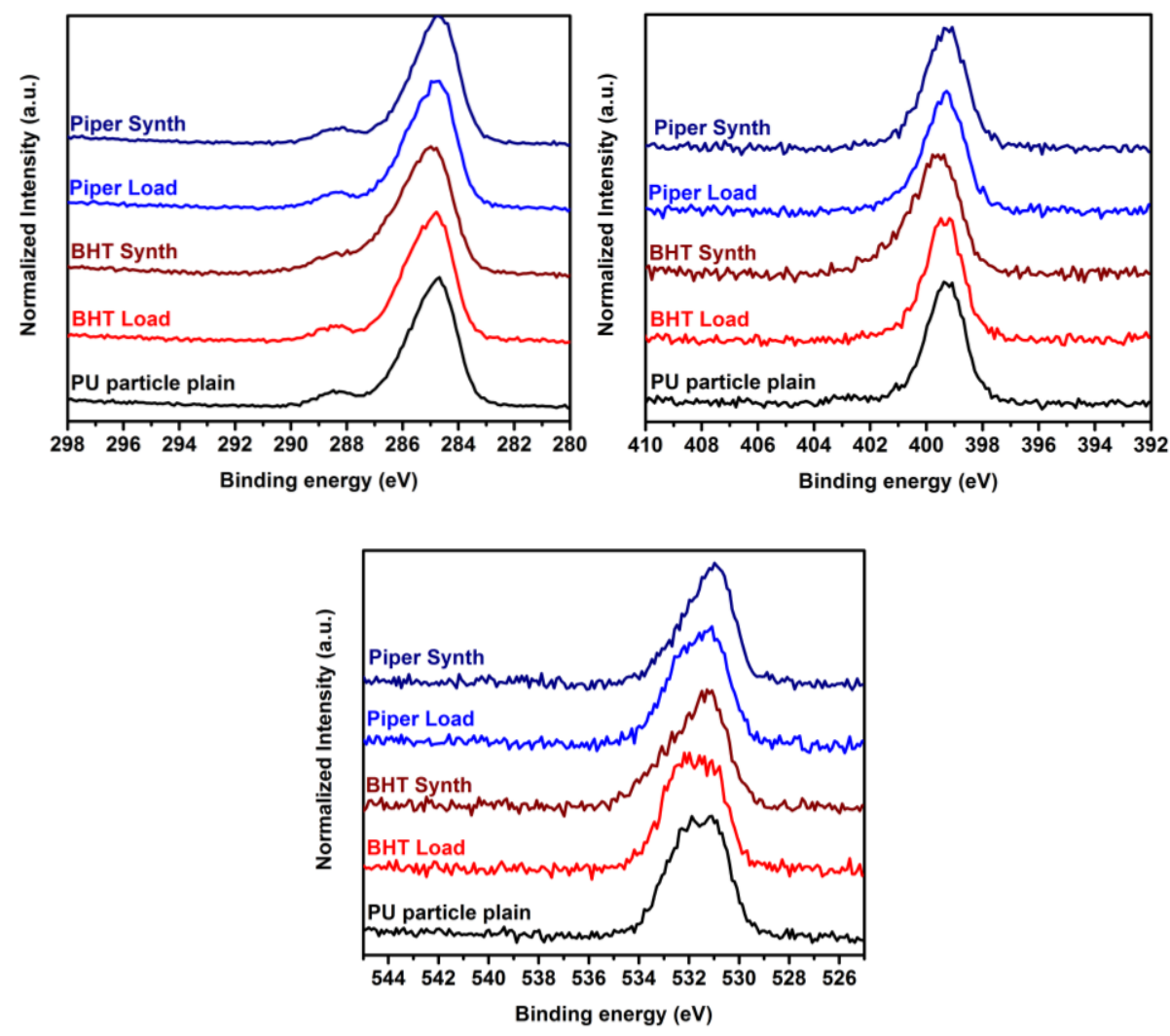

SI Figure 13. XPS spectra of example particles comparing the effects of loading during synthesis compared with post synthesis of Piper and BHT antioxidants. (C1s (298-280 eV), N1s (410-392 eV), O1s (545-525 eV)). 

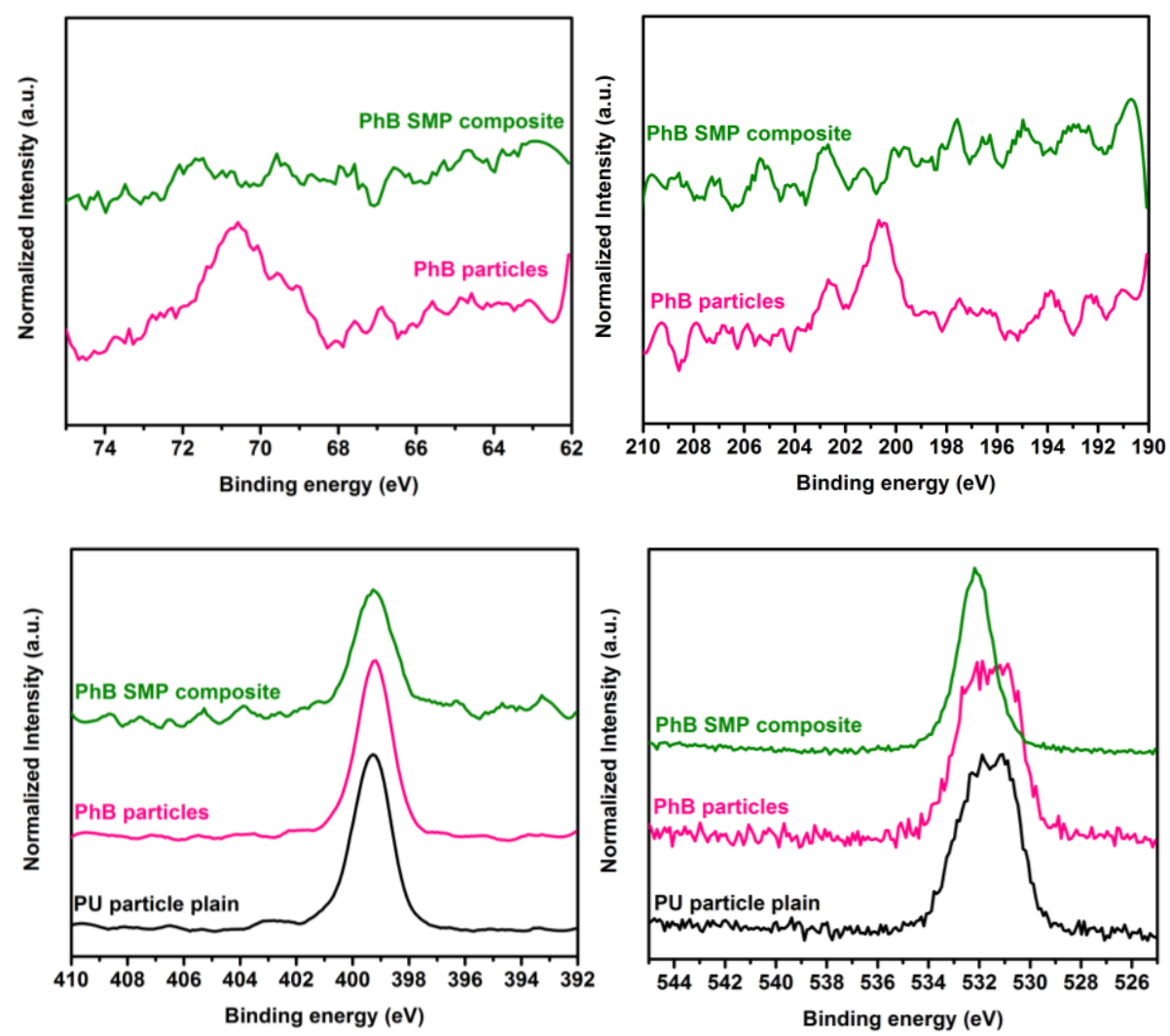

SI Figure 14. XPS spectra of Br3p (75-62 eV), Cl2s (210-190 eV), N1s (410-392 eV), O1s (545$525 \mathrm{eV}$ ) for PhB-containing SMPs and particles. 

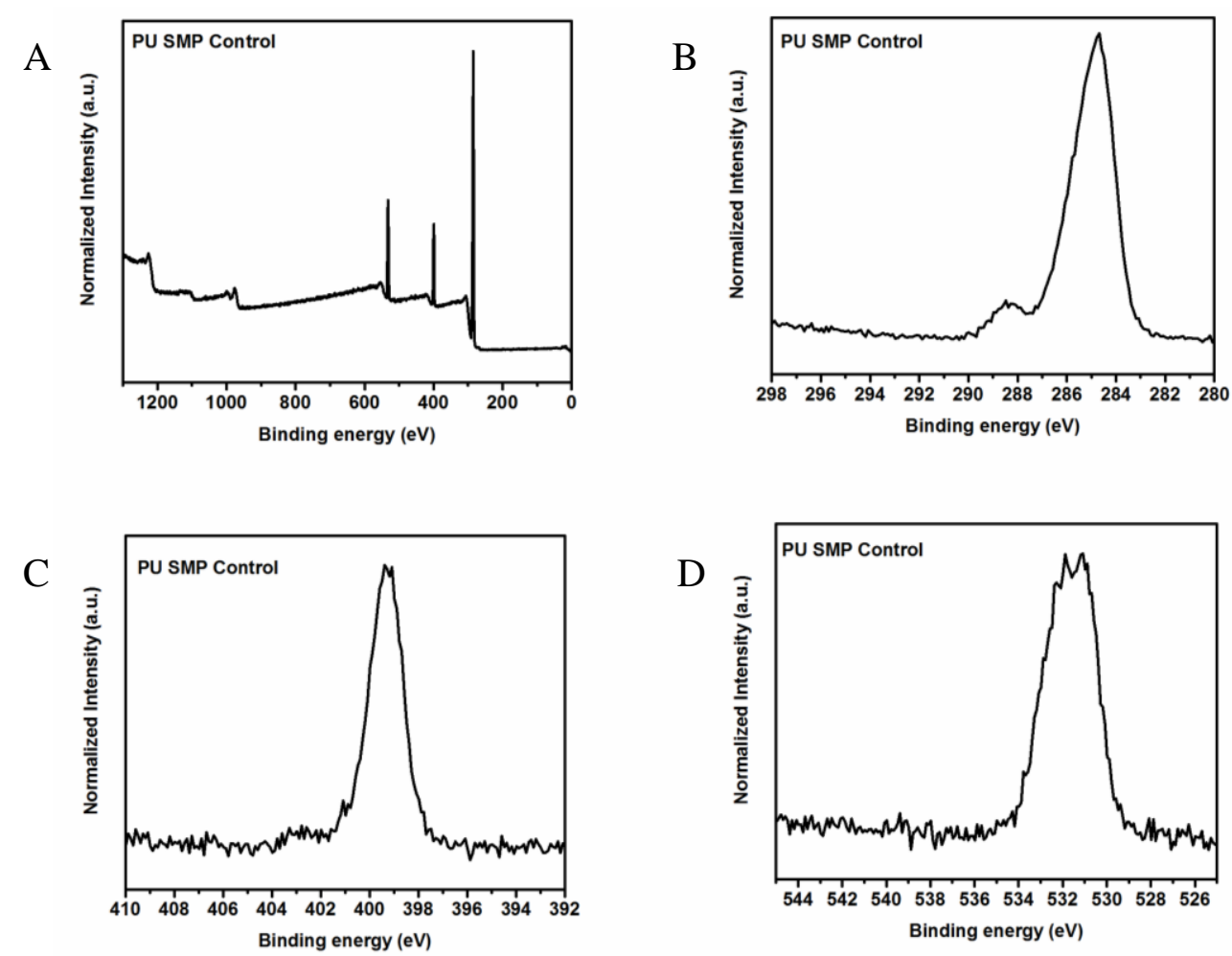

SI Figure 15. XPS spectra displaying control SMP formulations, displaying the survey scan (A) and specific elemental scans (C1s (298-280 eV, B), N1s (410-392 eV, C), O1s (545-525 eV, D)). 

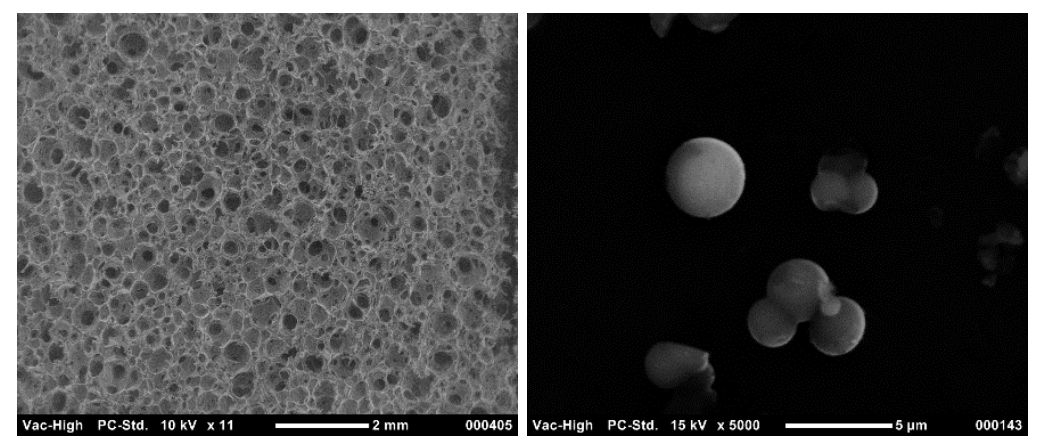

SI Figure 16. SEM image of Nile particle SMP composite of foam pores containing microparticles in struts (left), and individual particles (right).
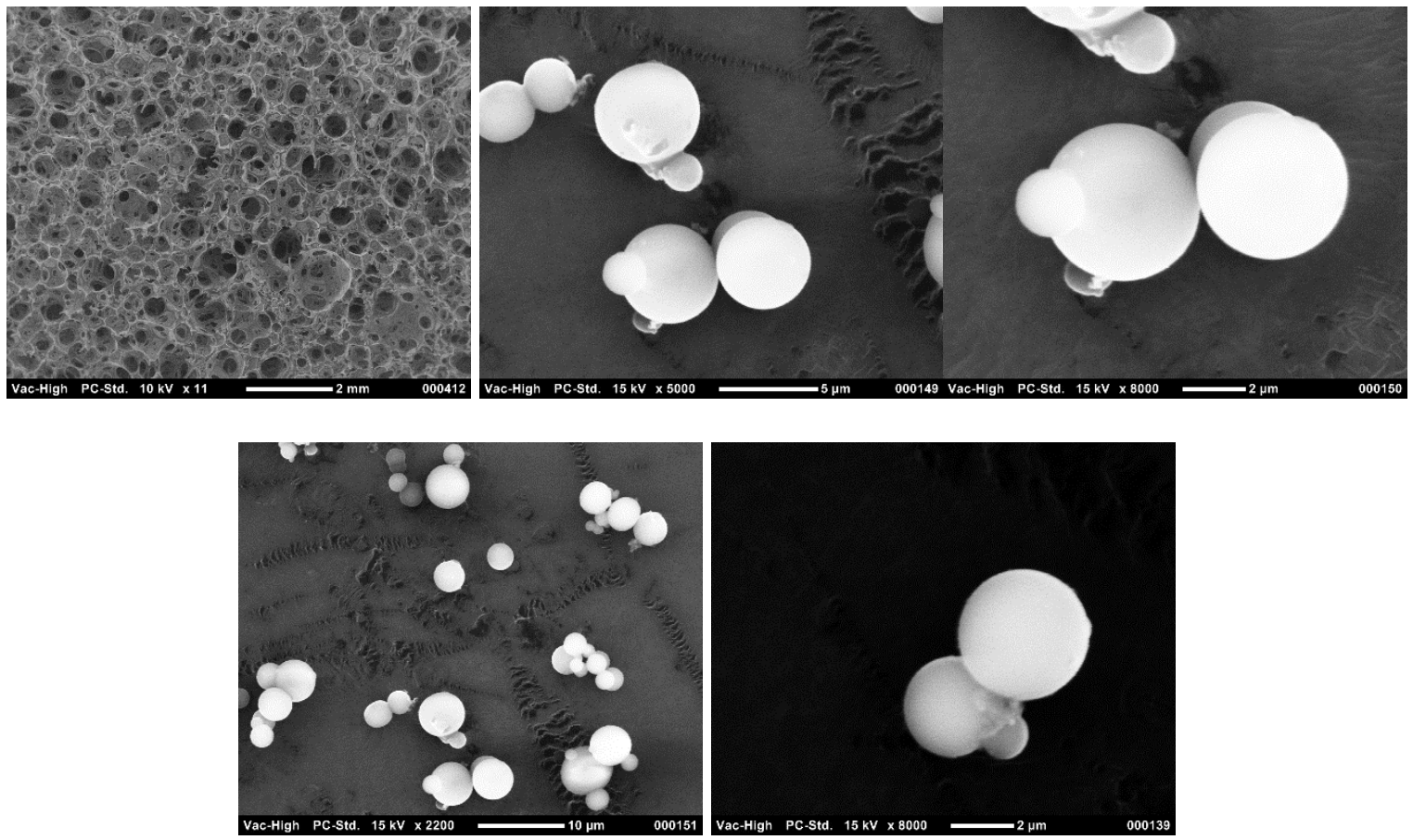

SI Figure 17. SEM image of PhB particle SMP composite (top left) and SEM images of particles (top center, top right, and bottom). 
SI Table 1. Mechanical properties of small molecule antioxidant-containing SMPs using HDI and $60 \%$ TEA $/ 40 \%$ HPED alcohol ratio; all samples were tested at room temperature at 5 $\mathrm{mm} / \mathrm{min}$ for ASTM Type IV dogbones.

\begin{tabular}{l|llll}
$\begin{array}{l}\text { Foam } \\
\text { Composition }\end{array}$ & Elastic Modulus (MPa) & Strain-to-Failure (\%) & $\begin{array}{l}\text { Tensile Strength } \\
(\mathrm{MPa})\end{array}$ & Toughness $\left(\mathrm{J}^{*} \mathrm{~m}^{4}\right)$ \\
\hline $\begin{array}{l}\text { Control } \\
\text { Piper }\end{array}$ & $0.25 \pm 0.06$ & $165 \pm 21$ & $0.41 \pm 0.08$ & 333.1 \\
Methyl & $0.28 \pm 0.19$ & $167 \pm 27$ & $0.61 \pm 0.23$ & 786.9 \\
BHT & $2.32 \pm 0.44$ & $104 \pm 27$ & $1.77 \pm 0.46$ & 1263.8 \\
Thio & $0.24 \pm 0.06$ & $176 \pm 39$ & $0.97 \pm 0.14$ & 940.1 \\
Triphen & $0.24 \pm 0.06$ & $181 \pm 49$ & $0.81 \pm 0.21$ & 722.6 \\
& $0.11 \pm 0.02$ & $131 \pm 21$ & $0.35 \pm 0.06$ & 204.5
\end{tabular}
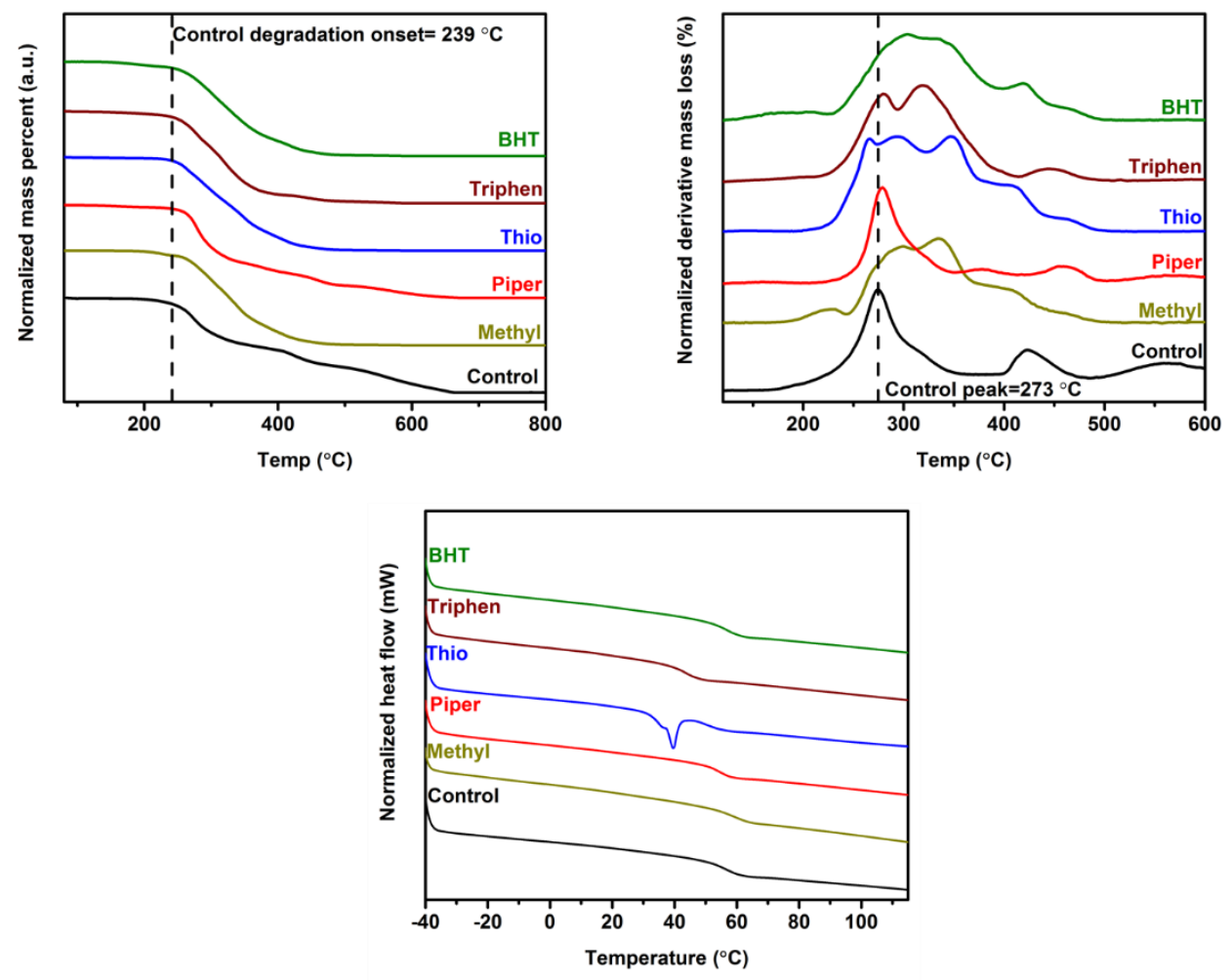

SI Figure 18. Thermal analysis of antioxidant-containing foams, displaying TGA (top) and DSC (below) thermograms. BHT, Piper, Thio, and Methyl seemed to delay thermal oxidation; after extractions, Thio still appeared to be in the SMP matrix, as did Methyl, Piper, and BHT (Triphen seemed to have been extracted out). 


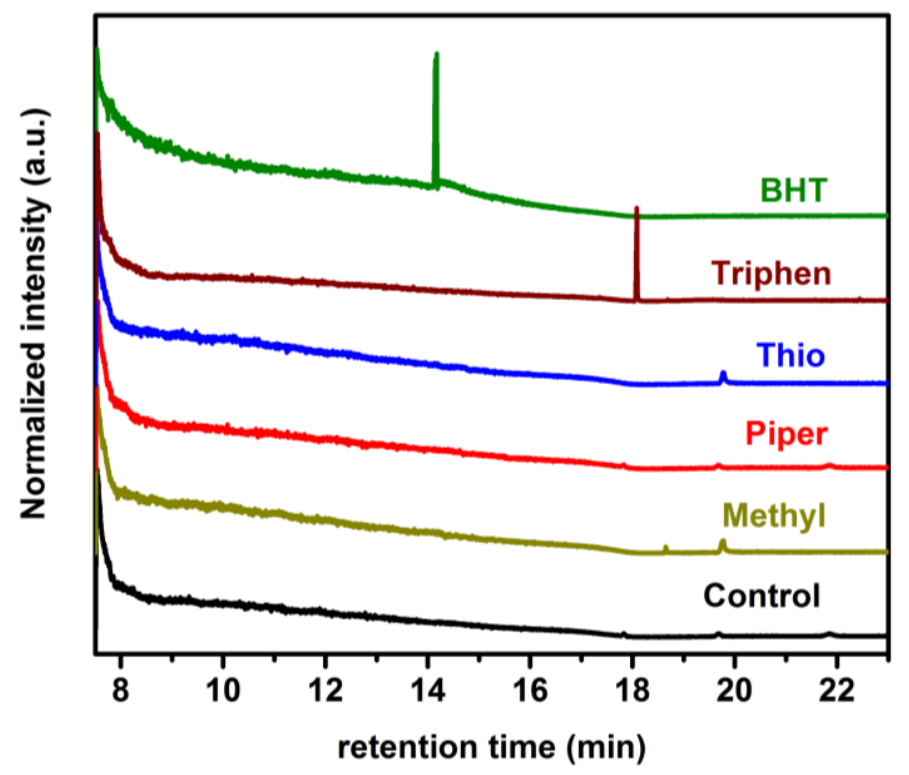

SI Figure 19. GCMS chromatographs for antioxidants extracted from SMPs.

SI Table 2. Mass and concentration of antioxidants added during synthesis and extracted during cleaning, determined using GC/MS.

\begin{tabular}{|l|l|l|l|l|}
\hline & $\begin{array}{l}\text { Additive Mass } \\
(\mathrm{g})\end{array}$ & $\begin{array}{l}\text { Additive } \\
\text { Concentration } \\
(\mathrm{mol})\end{array}$ & $\begin{array}{l}\text { Extract Mass } \\
(\mathrm{g})\end{array}$ & $\begin{array}{l}\text { Extract } \\
\text { Concentration } \\
(\mathrm{mol})\end{array}$ \\
\hline Piper & 2.000 & 0.012 & 0.080 & 0.000 \\
\hline Methyl & 2.000 & 0.006 & 0.155 & 0.000 \\
\hline Thio & 2.000 & 0.004 & 0.149 & 0.000 \\
\hline Triphen & 2.000 & 0.007 & 1.928 & 0.006 \\
\hline BHT & 2.000 & 0.009 & 1.629 & 0.007 \\
\hline
\end{tabular}



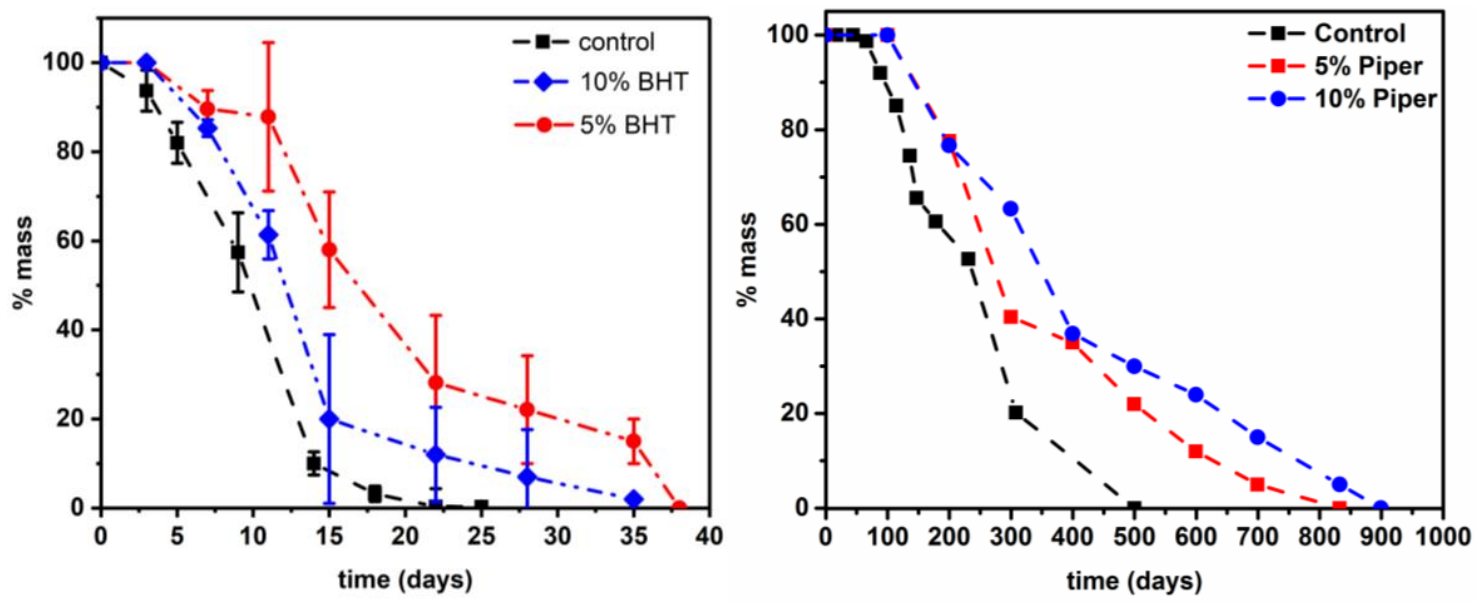

SI Figure 20. Accelerated oxidation of TMHDI SMPs containing BHT (left) and predicted real time oxidative mass loss of antioxidant (Piper) containing HDI-based SMPs (equivalent of $2 \% \mathrm{H}_{2} \mathrm{O}_{2}$ at $37^{\circ} \mathrm{C}$ ). 